OPEN ACCESS

Edited by:

Tram Pham

Montreal Clinical Research Institute

(IRCM), Canada

Reviewed by:

Mariana Gisela Bego,

McGill University, Canada

Ludovic Desvignes,

NYU Grossman School of Medicine,

United States

*Correspondence: Javier Castillo-Olivares fjc37@cam.ac.uk

${ }^{\dagger}$ Present address: Minna Paloniemi, Fimlab Laboratories Ltd, Tampere, Finland

FThese authors have contributed equally to this work

Specialty section: This article was submitted to Viral Immunology, a section of the journal Frontiers in Immunology

Received: 27 July 2021 Accepted: 22 October 2021 Published: 19 November 2021

Citation: Castillo-Olivares J, Wells DA, Ferrari M, Chan ACY, Smith $P$, Nadesalingam A, Paloniemi M, Carnell GW, Ohlendorf L, Cantoni D, Mayora-Neto M, Palmer P,

Tonks $P$, Temperton NJ, Peterhoff $D$,

Neckermann $P$, Wagner $R$,

Doffinger $R$, Kempster $S$, Otter $A D$,

Semper A, Brooks T, Albecka A, James $L C$, Page $M$, Schwaeble $W$, Baxendale H and Heeney JL (2021) Analysis of Serological Biomarkers

of SARS-CoV-2 Infection in Convalescent Samples From Severe, Moderate and Mild COVID-19 Cases.

Front. Immunol. 12:748291. doi: 10.3389/fimmu.2021.748291

\section{Analysis of Serological Biomarkers of SARS-CoV-2 Infection in Convalescent Samples From Severe, Moderate and Mild COVID-19 Cases}

\author{
Javier Castillo-Olivares ${ }^{1 *}$, David A. Wells ${ }^{1,2}$, Matteo Ferrari ${ }^{1,2}$, Andrew C. Y. Chan ${ }^{1}$, \\ Peter Smith ${ }^{1}$, Angalee Nadesalingam ${ }^{1}$, Minna Paloniemi ${ }^{1 \dagger}$, George W. Carnell ${ }^{1}$, \\ Luis Ohlendorf ${ }^{1}$, Diego Cantoni ${ }^{3}$, Martin Mayora-Neto ${ }^{3}$, Phil Palmer ${ }^{1}$, Paul Tonks ${ }^{1}$, \\ Nigel J. Temperton ${ }^{3}$, David Peterhoff ${ }^{4}$, Patrick Neckermann ${ }^{4}$, Ralf Wagner ${ }^{4,5}$, \\ Rainer Doffinger ${ }^{6}$, Sarah Kempster ${ }^{7}$, Ashley D. Otter ${ }^{8}$, Amanda Semper ${ }^{8}$, Tim Brooks ${ }^{8}$, \\ Anna Albecka ${ }^{9}$, Leo C. James ${ }^{9}$, Mark Page ${ }^{7}$, Wilhelm Schwaeble ${ }^{10 t}$, Helen Baxendale ${ }^{11 \neq}$ \\ and Jonathan L. Heeney ${ }^{1 \neq}$

\begin{abstract}
${ }^{1}$ Lab of Viral Zoonotics, Department of Veterinary Medicine, University of Cambridge, Cambridge, United Kingdom, Germany, ${ }^{6}$ Department of Clinical Biochemistry and Immunology, Addenbrooke's Hospital, Cambridge, United Kingdom, ${ }^{7}$ Division of Virology, National Institute for Biological Standards and Control, Potters Bar, United Kingdom, ${ }^{8}$ UK Health Security Agency, Porton Down, United Kingdom, ${ }^{9}$ MRC Laboratory of Molecular Biology, Cambridge, United Kingdom, ${ }^{10}$ Complement Laboratory, Department of Veterinary Medicine, University of Cambridge, Cambridge, United Kingdom,

${ }^{11}$ Royal Papworth Hospital NHS Foundation Trust, Cambridge, United Kingdom
\end{abstract} \\ ${ }^{2}$ DIOSynVax, University of Cambridge, Cambridge, United Kingdom, ${ }^{3}$ Viral Pseudotype Unit, Medway School of Pharmacy, \\ University of Kent, Chatham, United Kingdom, ${ }^{4}$ Institute of Medical Microbiology and Hygiene, University of Regensburg, \\ Regensburg, Germany, ${ }^{5}$ Institute of Clinical Microbiology and Hygiene, University Hospital Regensburg, Regensburg,
}

Precision monitoring of antibody responses during the COVID-19 pandemic is increasingly important during large scale vaccine rollout and rise in prevalence of Severe Acute Respiratory Syndrome-related Coronavirus-2 (SARS-CoV-2) variants of concern (VOC). Equally important is defining Correlates of Protection (CoP) for SARS-CoV-2 infection and COVID-19 disease. Data from epidemiological studies and vaccine trials identified virus neutralising antibodies (Nab) and SARS-CoV-2 antigen-specific (notably RBD and S) binding antibodies as candidate CoP. In this study, we used the World Health Organisation (WHO) international standard to benchmark neutralising antibody responses and a large panel of binding antibody assays to compare convalescent sera obtained from: a) COVID-19 patients; b) SARS-CoV-2 seropositive healthcare workers $(\mathrm{HCW})$ and $\mathrm{c})$ seronegative $\mathrm{HCW}$. The ultimate aim of this study is to identify biomarkers of humoral immunity that could be used to differentiate severe from mild or asymptomatic SARS-CoV-2 infections. Some of these biomarkers could be used to define CoP in further serological studies using samples from vaccination breakthrough and/or re-infection cases. Whenever suitable, the antibody levels of the samples studied were expressed in International Units (IU) for virus neutralisation assays or in Binding Antibody Units (BAU) for ELISA tests. In this work we used commercial and non-commercial antibody binding assays; a lateral flow test for detection of SARS-CoV-2-specific lgG/lgM; a high throughput 
multiplexed particle flow cytometry assay for SARS-CoV-2 Spike (S), Nucleocapsid (N) and Receptor Binding Domain (RBD) proteins); a multiplex antigen semi-automated immunoblotting assay measuring lgM, IgA and lgG; a pseudotyped microneutralisation test (pMN) and an electroporation-dependent neutralisation assay (EDNA). Our results indicate that overall, severe COVID-19 patients showed statistically significantly higher levels of SARSCoV-2-specific neutralising antibodies (average $1029 \mathrm{JU} / \mathrm{ml}$ ) than those observed in seropositive HCW with mild or asymptomatic infections $(379 \mathrm{IU} / \mathrm{ml})$ and that clinical severity scoring, based on WHO guidelines was tightly correlated with neutralisation and $\mathrm{RBD} / \mathrm{S}$ antibodies. In addition, there was a positive correlation between severity, Nantibody assays and intracellular virus neutralisation.

Keywords: COVID-19, SARS-CoV-2, Serological biomarkers, Antibodies, WHO International Standard, Correlates of Protection, COVID-19 immune response

\section{INTRODUCTION}

From the moment the World Health Organisation (WHO) declared COVID-19 a Public Health Emergency of International Concern (1), SARS-CoV-2 continued its global spread and caused more than 3 million deaths up to April 2021 (2). A total of 184 candidate vaccines are now in pre-clinical development and 92 have entered the clinical phase. Of the latter, seven vaccines have been approved by National Regulatory Authorities in different parts of the world and WHO have issued Emergency Use Listing for four of these (3). All these developments occurred in less than a year, thanks to the unprecedented joint effort made by the scientific community, WHO and other international public-health entities, the pharmaceutical Industry and philanthropic organisations. Because a defined Correlate of Protection (CoP) to COVID-19 did not exist, and still remains elusive, the efficacy of these vaccines was evaluated in large placebo-controlled clinical trials involving large numbers of participants exposed naturally to SARS-CoV-2 in countries that had active COVID-19 epidemics (4). Though successful, this process was very costly and logistically demanding. The last few months of the pandemic are being characterised by the emergence of SARS-CoV-2 variants that carry mutations that resulted in increased transmissibility, increased pathogenicity or increased potential to evade the immune response of the host (5). Determining the vaccine efficacy against these variants of concern (VOC) is of high priority for regulatory bodies and vaccine manufacturers in the coming months or perhaps years.

In the absence of a universally accepted CoP against COVID19, data from Phase III clinical trials suggested that virus neutralising antibodies $(\mathrm{nAb})$ are a candidate $\mathrm{CoP}$ (6). Likewise, observations made on the natural history of COVID19 indicated the association of $\mathrm{nAb}$ and protection (7). However, the protective threshold for $\mathrm{nAb}$ has been difficult to establish in different settings. Early studies comparing clinical progression and case fatality rates found that the magnitude of the antibody response correlated with the severity of disease (8-10). Patients with fatal outcomes often had the strongest IgG responses to nucleoprotein $(\mathrm{N})$, and were often accompanied by marked responses to the Spike (S) protein (11). Furthermore, patients with severe disease have also been reported to have high $\mathrm{nAb}$ titres $(12,13)$, with studies showing a strong correlation between live-virus or pseudotype based micro-neutralisation (pMN) and anti-Spike antibody binding assays $(10,14)$.

Cellular immune responses directed against internal viral antigens often play an important role in the clearance of viral infections. The effector mechanisms of anti-viral immunity of non-neutralising antibodies are becoming better understood (15, 16) and it is often that these are directed against viral internal antigens, such as the $\mathrm{N}$ antigen of SARS-CoV-2. One of these mechanisms is mediated by the cytosolic antibody receptor TRIM21 (17), which captures antibody-antigen complexes and accelerates their degradation and processing through the proteasome, facilitating the loading of antigenic peptides in nascent MHC molecules and promoting antigen presentation to $\mathrm{T}$ cells (18). While the latter study focused on antibodies against the nucleoprotein of the enveloped positive strand RNA virus LCMV, it is possible that antibodies directed against the $\mathrm{N}$ antigen of SARS-CoV-2 function in a similar way. We therefore analysed TRIM21-mediated biomarkers of immunity in our cohorts using established methods (19) to determine the holistic role of antibodies in protection from COVID-19 disease.

One of the factors that have precluded the derivation of welldefined humoral $\mathrm{CoP}$ in general, and to COVID-19 disease in particular, is the diverse number of quantitative antibody assays available and the different units used to quantify the antibody levels of clinical samples. Measuring nAb against SARS-CoV-2 is typically done by virus neutralisation tests such as plaque reduction neutralisation test (PRNT), infectious centre assays or micro-neutralisation tests (20-24). These are performed with live SARS-CoV-2 or with pseudotyped viruses (typically lentivirus or vesicular stomatitis virus) displaying SARS-CoV-2 Spike protein in their envelope. The antibody levels of these assays are quantified in serum titres for specific percentages of neutralisation (i.e. $\mathrm{PRNT}_{50}, \mathrm{PRNT}_{80}$ ), or as $\mathrm{IC}_{50}$ or other readouts. The choice of antibody binding assays is also varied, from the traditional ELISA format to more refined commercial assays (ECLIA, multiplexed micro-sphere assays, semiautomated immunoblotting assays). These methods use the 
Spike protein or sub-domains thereof or internal nucleoprotein as target antigens. The readouts of these assays are expressed using a diverse suite of units such as antibody titre, OD (optical density) values for specific wave lengths (450 nm, $490 \mathrm{~nm})$ or mean fluorescent intensity (MFI) units or Chemiluminescent units (MCI). In order to harmonise results of quantitative COVID-19 immuno-assays, the WHO has advocated the use of the 'International Standard for SARS-CoV-2 immunoglobulin' (NIBSC code '20/136') as a primary assay calibrant $(25,26)$. We used this reagent and its assigned unitage (1000 units $/ \mathrm{ml}$ ) as a reference to derive, in International Units (IU), the potency of our 'in-house' internal assay calibrants. In this way, antibody levels of samples tested by either neutralisation of antibody binding assays can be expressed in IU or Binding Antibody Units per $\mathrm{ml}(\mathrm{BAU} / \mathrm{ml})$ and thus immunogenicity and vaccine efficacy data can be compared between different laboratories.

The Humoral Immune Correlates for COVID-19 Project (HICC) aims to dissect the humoral immune response to SARS-CoV-2 and identify the mechanisms of immunity that protect from COVID-19 and to distinguish them from proinflammatory and complement responses leading to severe disease. The specific aim of the present study is to define antibody-based biomarkers that differentiate severe from mild/ asymptomatic COVID-19 cases. These antibody based parameters can also be used to define CoP in vaccine breakthrough and/or re-infection studies. Wherever possible, we expressed these antibody measurements in IU or BAU. Towards this objective, we have analysed the antibody levels and antigenic specificity of convalescent antibody samples of HCWs and hospitalised COVID-19 patients exposed and infected during the first pandemic wave (between March 2020 - October 2020) in the UK. This study defines the methods and findings establishing a benchmark for future longitudinal studies to define COVID-19 CoP.

\section{MATERIALS AND METHODS}

\subsection{Selection of Sera and Plasma}

Serum and plasma samples were obtained from healthcare workers (HCW) and patients referred to the Royal Papworth Hospital, Cambridge, UK for critical care. COVID-19 patients hospitalised during the first wave and as well as NHS healthcare workers working at the Royal Papworth Hospital in Cambridge, UK, served as the exposed HCW cohort (Study approved by Research Ethics Committee Wales, IRAS: 96194 12/WA/0148. Amendment 5). NHS HCW participants from the Royal Papworth Hospital were recruited through staff email over the course of two months (20 ${ }^{\text {th }}$ April 2020-10 ${ }^{\text {th }}$ June 2020) as part of a prospective study to establish seroprevalence and immune correlates of protective immunity to SARS-CoV-2. Patients were recruited in convalescence either pre-discharge or at the first post-discharge clinical review. All participants provided written, informed consent prior before enrolment in the study. Sera from NHS HCW and patients were collected between July and September 2020, 3-5 months after they were enrolled in the study.

Clinical assessment and WHO criteria scoring of severity for both patients and NHS HCW (Table 1) was conducted following the 'COVID-19 Clinical Management: living guidance' (27).

For cross-sectional comparison, representative convalescent serum and plasma samples were collected from seronegative HCWs, seropositive HCW and convalescent PCR-positive COVID-19 patients. The serological screening to classify convalescent HCW as positive or negative was done according to the results provided by a UKAS-accredited Luminex assay detecting N-, RBD- and S-specific IgG, a lateral flow diagnostic test (IgG/IgM) and an Electro-chemiluminescence assay (ECLIA) detecting $\mathrm{N}$ - and S-specific IgG. Any sample that produced a positive result by any of these assays was classified as positive. The severity score of the individuals from which the sample was obtained ranged from 0 to 7 according to the WHO classification described above. Thus, the panel of convalescent serum samples (3-5 months post-infection) were grouped in three categories: a) Patients ( $n=38)$; b) Seropositive HCW ( $n=24$ samples); and c) Seronegative HCW $(n=39)$ (Table 2).

\subsection{Internal and External Calibration Reagents}

The reference reagents used as external, or primary calibrants in our assays included: a) the First WHO International Standard for anti-SARS-CoV-2 immunoglobulin (NIBSC 20/136); b) the Anti-SARS-CoV-2 Antibody Diagnostic Calibrant (NIBSC 20/ 162; and $\mathrm{c}$ ) the Research Reagent for anti-SARS-CoV-2 Ab (NIBSC 20/130). Details of these are described in the NIBSC catalogue (28).

TABLE 1A | Severity score classification.

\begin{tabular}{|c|c|c|}
\hline $\begin{array}{l}\text { Severity } \\
\text { Code }\end{array}$ & Severity Name & Description \\
\hline 1 & Asymptomatic & \\
\hline 2 & Mild Disease & Case definition without of COVID-19 without pneumonia \\
\hline 3 & Moderate pneumonia & Fever, cough, dyspnoea, $\mathrm{SpO}_{2}>90 \%$ \\
\hline 4 & Severe pneumonia & Fever, dyspnoea, cough plus $\mathrm{RR}>30, \mathrm{SpO}_{2}<90 \%$ requirement; \\
\hline 5 & $\begin{array}{l}\text { ARDS (Acute Respiratory Distress } \\
\text { Syndrome) }\end{array}$ & diffuse bilateral infiltrates $\mathrm{PaO} 2 / \mathrm{FiO} 2<300$ \\
\hline 6 & Sepsis & $\begin{array}{l}\text { Life-threatening organ disfunction: severe dyspnoea, delirium, low } 02 \text { saturation, oliguria, tachycardia, weak pulse, } \\
\text { low blood pressure, coagulopathy }\end{array}$ \\
\hline 7 & Septic Shock & As above plus Vasopressor requirement \\
\hline
\end{tabular}


TABLE 1B | Cohort demographic and severity score classification.

\begin{tabular}{lccccccc}
\hline & \multicolumn{7}{c}{ Symptom Severity Score } \\
\cline { 2 - 8 } & $\mathbf{1}$ & $\mathbf{2}$ & $\mathbf{3}$ & $\mathbf{4}$ & $\mathbf{5}$ & $\mathbf{6}$ & $\mathbf{7}$ \\
\hline Patients & 2 & 3 & 0 & 15 & 1 & 2 & 15 \\
HCW-P & 4 & 12 & 8 & 0 & 0 & 0 & 0 \\
HCW-N & 22 & 13 & 3 & 0 & 0 & 0 & 0
\end{tabular}

We used these external reference reagents to calculate the unitage of tested samples and/or to calibrate our own Internal (or secondary) assay calibrants. The latter were obtained from NHS healthcare workers exposed to SARS-CoV-2. Thus, HICC Serum-1 and HICC Serum-2 were pooled serum samples collected from RT-PCR-confirmed SARS-CoV-2-infected NHS personnel 2 months after presenting moderate symptoms of COVID-19.

\subsection{Pre-Pandemic Plasma}

A panel of 23 pre-pandemic plasma collected between 2016 and 2019, obtained from the National Institute of Biological Standards and Control (NIBSC), was used to set up the negative cut-off point of the quantitative immunoblotting assay, the pan-Ig N- and RBD-ELISA and the pMN assays.

\subsection{Detection of Total Antibody (Pan-Ig) Against SARS-CoV-2 Spike (S) and Nucleocapsid (N) Antigens by ELISA}

Two different ELISA tests were used for the detection of $\mathrm{N}$ specific and S-specific antibodies. The assays were adapted from those originally described by Amanat and co-workers (29). Briefly, Nunc MaxiSorp ${ }^{\text {TM }}$ flat-bottom plates were coated with $50 \mu \mathrm{l}$ per well of $1 \mu \mathrm{g} / \mathrm{ml}$ of either RBD or $\mathrm{N}$ antigen in DPSB $\left(-\mathrm{Ca}^{2+} /-\mathrm{Mg}^{2+}\right)$ and incubated overnight at $4^{\circ} \mathrm{C}$. The next day, the plates were blocked with $3 \%$ milk in PBST $(0.1 \% \mathrm{w} / \mathrm{v}$ Tween 20 in PBS) for 1 hour. After removing the blocking buffer, $50 \mu \mathrm{l} /$ well of serum samples, diluted in PBST-NFM ( $1 \% \mathrm{w} / \mathrm{w}$ non-fat milk in PBST) were added to the plates and incubated on a plate shaker for two hours at $20^{\circ} \mathrm{C}$. The plates were washed three times with $200 \mathrm{ml}$ of PBST, and $50 \mathrm{ml}$ of HRP-conjugated goat anti-human Ig ( $\mathrm{H}$ and $\mathrm{L}$ chains) (Jackson ImmunoResearch) diluted 1:3000 in PBST was added to each well and left to incubate for one hour on a plate shaker for 1 hour. Plates were washed three times with $200 \mu \mathrm{l}$ of PBST and $50 \mu \mathrm{l} /$ well of 1-Step Ultra TMB chromogenic substrate (Sigma) were added to the plates and the chemical reaction was stopped three minutes later with $50 \mu \mathrm{l} 2 \mathrm{~N} \mathrm{H}_{2} \mathrm{SO}_{4}$. The optical density at a wavelength of $450 \mathrm{~nm}$ (OD450) was measured using a Biorad microplate reader.

All test runs included, in addition to the test sample dilutions, an internal calibrant dilution series (HICC Serum 2), a single dilution of a positive control per plate (NIBSC 20/130), a negative control sample (NIBSC 15/288) per plate and a blank control (no primary antibody or sample). All samples were tested in duplicate and the duplicate readings were used to fit the standard curve. The blank readings were subtracted from the serum sample values. The $\mathrm{IC}_{50}$ values of each sample dilution series were determined and expressed as relative potency respect to the Internal Calibrant, for which a unitage in ELISA binding units was calculated using the WHO International Standard 20/ 136 as a reference. Details of how these were calculated are described in the 'Results' section.

\subsection{Roche Elecsys ${ }^{\circledR}$ Electrochemiluminescence Immunoassay (ECLIA)}

Samples were tested on Roche cobas ${ }^{\circledR}$ e801 analyser at PHE Porton Down. Anti-nucleocapsid protein antibodies were detected using the qualitative Roche Elecsys ${ }^{\circledR}$ Anti-SARS-CoV2 (ACOV2) ECLIA (Product code: 09203079190), whilst antiRBD antibodies were detected using the quantitative Roche Elecsys ${ }^{\circledR}$ Anti-SARS-CoV-2 S (ACOV2 S) ECLIA (Product code 092892751902), as previously described $(30,31)$. Both assays detect total antibodies (IgG, IgA and IgM). All kits were calibrated based on a two-point calibration curve according to the manufacturer's instructions, with daily QC performed per reagent pack. Anti-NP results are expressed as a cut-off index (COI) value, with a $\mathrm{COI} \geq 1$ interpreted as positive. Anti-spike results are expressed as units per $\mathrm{ml}(\mathrm{U} / \mathrm{ml})$, with results of $\geq 0.8$ $\mathrm{U} / \mathrm{ml}$ interpreted as positive and a quantitative range of 0.4 to 2,500 U/ml.

\subsection{Detection of SARS-CoV-2-S, -RBD and -N specific Antibodies Using a Multiplex Bead Flow Cytometry Platform, Luminex ${ }^{\text {TM }}$ Platform}

Detection of serum IgG reactive to SARS-CoV-2 N, S and RBD (receptor binding domain) antigens was done using a Luminex based assay following the methods previously described $(32,33)$. The amino acid sequences used derived from the $\mathrm{S}$ ectodomain

TABLE 2 | Cohorts. Classification of participants according to the serological screening of the sera by the ECLIA, multiplex Micros-sphere, and lateral flow assays.

\begin{tabular}{|c|c|c|c|c|c|c|c|c|c|c|}
\hline \multirow[t]{2}{*}{ Assay Platform } & \multirow[t]{2}{*}{ Antigen/Isotype } & \multicolumn{3}{|c|}{ Patients } & \multicolumn{3}{|c|}{ Seropositive Staff } & \multicolumn{3}{|c|}{ Seronegative Staff } \\
\hline & & Pos. & Neg. & ND & Pos. & Neg. & ND & Pos. & Neg. & ND \\
\hline \multirow[t]{3}{*}{ Luminex } & $N$ & 36 & 2 & 0 & 22 & 2 & 0 & 0 & 38 & 1 \\
\hline & S & 36 & 2 & 0 & 19 & 5 & 0 & 0 & 38 & 1 \\
\hline & RBD & 36 & 2 & 0 & 18 & 6 & 0 & 0 & 38 & 1 \\
\hline \multirow[t]{2}{*}{ Roche } & RBD & 34 & 2 & 2 & 18 & 6 & 0 & 0 & 36 & 3 \\
\hline & $\mathrm{N}$ & 34 & 2 & 2 & 18 & 6 & 0 & 0 & 36 & 3 \\
\hline \multirow[t]{2}{*}{ Lateral Flow } & $\lg G$ & 35 & 2 & 1 & 20 & 4 & 0 & 0 & 39 & 0 \\
\hline & $\lg M$ & 19 & 15 & 1 & 15 & 9 & 0 & 0 & 39 & 0 \\
\hline
\end{tabular}


derived from the BetaCoV/Wuhan/WIV04/2019 sequence. All samples were tested in duplicate and all test runs included a serum positive control, a serum negative control, and BSA and LPS antigen controls as blanks. Results outputs were expressed in MFI units. A machine training algorithm was used to assign a final serological classification to all the samples studied, as described previously (33). This method assigns a SARS-CoV-2 serological status considering the values the IgG values (MFI) for the three antigens. The negative cut off values for N-, RBD- and S-specific IgG assays were set up at 1604, 456 and 1896 respectively.

\subsection{SARS-CoV-2 Pseudotype-Based Microneutralisation Assay (pMN)}

Virus neutralising antibodies were detected and quantified by a pseudotype-based neutralisation assay based on a lentiviral system that enables the generation of replication-defective recombinant human immunodeficiency virus (HIV) displaying the Spike protein of SARS-CoV-2 on their viral envelope, as previously described $(34,35)$. Briefly, HEK293T cells were seeded in $10 \mathrm{~cm}^{2}$ cell culture dishes at a density to achieve $70 \%$ confluency after 24 hours for next day transfection. HEK293T cells were maintained in DMEM (Dulbecco Minimum Essential Medium) containing 10\% foetal bovine serum and 1\% penicillin/ streptomycin, at $37^{\circ} \mathrm{C}$ and $5 \% \mathrm{CO}_{2}$. Cell maintenance was done by three cell passages per week.

On the day of transfection, the culture medium was replaced with fresh complete DMEM. Cells were transfected with $1000 \mathrm{ng}$ of pcDNA-SARS-CoV-2 Spike plasmid, 1000ng of HIV 8.91 gag/ pol plasmid and 1500ng of pCSFLW luciferase plasmid, using FuGENE HD (Promega, UK), at a 1:3 ratio (plasmid:FuGENE HD). The culture media was harvested 48 hours posttransfection and filtered through a $0.45 \mu \mathrm{m}$ filter. The filtered pseudotype virus (PV) was aliquoted, titrated and stored at $-80^{\circ} \mathrm{C}$. Titration of PVs was carried out in a 96 well white plate typically using doubling serial dilutions. Pre-transfected HEK293T target cells expressing human ACE2 and TMPRSS2 were seeded at $10^{4}$ cells per well and plates were incubated for 48 hours prior to the addition of Bright-Glo reagent (Promega, UK) and reading the result in a luminometer.

For detecting and quantifying neutralising antibodies, serial doubling dilutions of the plasma samples in complete DMEM were performed from an initial $1 / 40$ dilution. SARS-CoV-2 PVs were added at $5 \times 10^{5}-5 \times 10^{6} \mathrm{RLU} / \mathrm{ml}$ in each well and the plates incubated for 1 hour in at $37^{\circ} \mathrm{C}, 5 \% \mathrm{CO}_{2}$ incubator. Post incubation, pre-transfected HEK293T target cells expressing human ACE2 and TMPRSS2 were seeded at $10^{4}$ cells per well and plates were incubated for 48 hours prior to the addition of Bright-Glo reagent and assaying using a luminometer.

In addition to the test sample dilutions, all test runs included dilution series of an external calibrant (NIBSC 20/162) or an internal calibrant (HICC Serum 2) and a single dilution of a positive control per plate (NIBSC 20/130). All samples were tested in duplicate and the average of the OD values determined. The $\mathrm{IC}_{50}$ values of each sample dilution series were determined and expressed as relative potency respect to the Internal or External Calibrant which enabled the expression of results in International Units using the WHO International Standard
$20 / 136$ as a primary calibrator. Details of how these were calculated are described in the 'Results' section.

\subsection{Semi-Automated Immunoblotting}

Plasma IgG antibodies reactive against the SARS-CoV-2 Spike and Nucleocapsid proteins were analysed by immuno-blotting using the 'Jess' fully automated system (ProteinSimple; BioTechne) and the SARS-CoV-2 Multi-Antigen Serology Module (ProteinSimple; Bio-Techne, SA-001), following the manufacturer's instructions. Here, the $12-230 \mathrm{kDa}$ Jess/Wes Separation Module was used. Briefly, the kit provides five SARS-CoV-2 recombinant viral antigens: RBD, N, S1 subunit, $\mathrm{S} 2$ subunit and $\mathrm{S}(\mathrm{S} 1+\mathrm{S} 2)$. The antigens were electrophoretically separated according to their molecular weight to create a ladder for capture of reactive antibodies. Two microlitres of plasma samples diluted 1:10 in diluent buffer were loaded. For the secondary antibody, ready to use HRP-conjugated goat antihuman IgG, IgA or IgM antibody was used. Digital image of chemiluminescence of the capillary was captured with the Compass Simple Western software (version 4.1.0, Protein Simple), that automatically calculated chemiluminescence intensity of each single antigen binding signal. Results could be visualized as electropherograms representing peak of chemiluminescence intensity and as lane view from signal of chemiluminescence detected in the capillary. To control for differences in signal between experiments, a reference sample, the NIBSC Anti-SARS-CoV-2 Antibody Diagnostic Calibrant (NIBSC 20/162) was included in each experiment. A panel of pre-pandemic plasma sera was used to calculate the negative cutoff value for each of the antigen tests (mean +2 STD). Final results of the samples were calculated by subtracting the negative cut-off value from the chemiluminescent signal of the sample.

\subsection{Lateral Flow IgG/IgM}

A rapid detection kit (Accu-Tell COVID-19 IgG/IgM Antibody Test) for SARS-CoV-2 was used following manufacturer's instructions and compared with other antibody detection platforms. Briefly, $5 \mu \mathrm{l}$ of heat-inactivated serum were added to the antigen test cassettes followed by 2 drops of the supplied PBS. After an incubation of $30 \mathrm{~min}$ at $20^{\circ} \mathrm{C}$, the results were recorded. A positive IgG or IgM result was indicated by the appearance of a band for either of the isotypes included in the assay. Tests were valid only if a control band appeared in the device.

\subsection{Electroporation-Dependent Neutralisation Assay (EDNA)}

Electroporation was performed using the Neon Transfection System (Thermo Fisher). Vero ACE2/TMPRSS2 cells (36) were washed with PBS and resuspended in Buffer R (Thermo Fisher) at a density of $1 \times 10^{6}$ cells per ml. For each electroporation reaction $0.5 \times 10^{6}$ cells $(10.5 \mu \mathrm{l})$ were mixed with $2 \mu \mathrm{l}$ of serum to be delivered. The mixture was taken up into a $10 \mu \mathrm{l}$ Neon Pipette Tip and electroporated using the following settings: $1400 \mathrm{~V}, 20 \mathrm{~ms}, 2$ pulses. Electroporated cells were transferred to medium supplemented with $10 \%$ serum without antibiotics. $1.5 \times 10^{4}$ electroporated cells were seeded into 96-well plates in triplicates and after $24 \mathrm{~h}$ transferred to containment level 3 laboratory. 
Supernatants were removed and all wells washed with PBS to remove any remaining antibodies that could interfere with virus entry. Cells were infected at moi $=1$ in DMEM supplemented with $2 \%$ FBS and antibiotics and incubated for $24 \mathrm{~h}$ to allow for a single replication cycle. The virus used was a derivative of the Wuhan virus, SARS-CoV-2/human/Liverpool/REMRQ0001/202, isolated by Lance Turtle (University of Liverpool) and David Matthews and Andrew Davidson (University of Bristol). After incubation, plates were immediately frozen at $-70^{\circ} \mathrm{C}$ to help with cell lysis. Next, plates were thawed at $4^{\circ} \mathrm{C}$ and 1 volume of lysis buffer (0.25\% Triton-X100, 50mM KCl, $100 \mathrm{mM}$ Tris- $\mathrm{HCl} \mathrm{pH} \mathrm{7.4,}$ glycerol $40 \%$ and RNAsecure from Invitrogen at 1/100) was added to wells and mixed gently by pipetting. After $5 \mathrm{~min}$ of lysis, cell lysates were transferred to PCR plates and virus inactivated at $95^{\circ} \mathrm{C}$ for $5 \mathrm{~min}$. RT-qPCR was performed with Luna ${ }^{\circledR}$ Universal Probe One-Step kit (E3006, NEB) following manufacturer recommendations. Primer/probe for genomic viral RNA were CDC-N2 (IDT 2019-nCoV RUO kit). Primer probe for $18 \mathrm{~S}$ control were described previously (37). SARS-CoV2_N_Positive control RNA from IDT (10006625) was used as standard for the viral genomic $\mathrm{N}$ reactions. For $18 \mathrm{~S}$ rRNA standard, DNA was synthesized and kindly gifted by Jordan Clarks and James Stewart (University of Liverpool). Final concentrations of $500 \mathrm{nM}$ for each primer and $125 \mathrm{nM}$ for the probe were used. RT-qPCR reactions were run on ABI StepOnePlus PCR System (Life Technologies) with following program: $55^{\circ} \mathrm{C}$ for $10 \mathrm{~min}, 95^{\circ} \mathrm{C}$ for $1 \mathrm{~min}$ and then 40 cycles of $95^{\circ} \mathrm{C}$ denaturation for $10 \mathrm{sec}$ and $60^{\circ} \mathrm{C}$ extension for $30 \mathrm{sec}$. RNA copy numbers were obtained from standards and then genomic copies of $\mathrm{N}$ normalised to $10^{10}$ copies of $18 \mathrm{~S}$. Finally, all data was normalized to $100 \%$ to PBS electroporated cells.

\subsection{Statistical Methods}

We calculated $\log \mathrm{IC}_{50}$ values to summarise the $\mathrm{RBD}$-specific and $\mathrm{N}$-specific antibodies as measured by ELISA and neutralising antibody titre as measured by neutralisation. $\log \mathrm{IC}_{50}$ values were estimated by fitting four parameter log-logistic regression dose response curves in the $\mathrm{R}$ package drc (38). The four parameters of this curve are the minimum response, the maximum response, the log of the dilution halfway between the two $\left(\mathrm{IC}_{50}\right)$, and the gradient at the $\mathrm{IC}_{50}$. Our models actually estimated the natural $\log$ of $\mathrm{IC}_{50}$ values because it improved model convergence and produced normally distributed values for downstream analyses.

To ensure $\mathrm{IC}_{50}$ values were comparable, a single gradient, minimum, and maximum value was estimated for dose response curves of all samples. To minimise noise between experimental runs the gradient, minimum, and maximum parameters were estimated based on a random subset of 200 samples and fixed for all other samples. Graphical checks showed that these parameters produced curves that fit the observed data well. We observed that this parameter fixing decreased the variance in estimated $\log \mathrm{IC}_{50}$ values for calibrants.

Samples and calibrants could be assigned an international unitage based on their potency relative to the international standard NIBSC 20/136 which has been assigned an arbitrary unitage of $1000 \mathrm{IU} / \mathrm{ml}$. Unitage for a sample was expressed as
Units of sample $=$ Calibrant units $\times$ Sample $\mathrm{IC}_{50} /$ Calibrant $\mathrm{IC}_{50}$

In practice, the unitage of calibrants was quantified in international units as shown above and the unitage of samples was calculated based on their potency relative to a calibrant with a known international unitage. The reason for this two-step process is that the international standard was not available until December 2020.

To assign international units to the calibrants, these were run in duplicate alongside the international standard and relative potencies and international units were calculated as described above. The assumption of parallel curves was verified by comparing the AIC of models which allowed separate gradients to those which did not.

The Spearman's rank correlation coefficient for variables pairs and Mann-Whitney U tests were calculated using R (39).

\section{RESULTS}

The primary objective of this work was to identify relevant biomarkers of humoral immunity that can serve to differentiate severe from mild/asymptomatic COVID-19 cases and also could be used as potential Correlates of Protection (CoP) of COVID19. In this study we analysed antibody-based parameters present in serum or plasma of convalescent patients and compared these antibody levels to those in seropositive and seronegative healthcare workers (HCW).

\subsection{Clinical Details of Patients and Healthcare Workers Included in this Study}

The participants of this study were classified into three cohorts: a) Patients; b) Seropositive HCW; and c) Seronegative HCW (Table 2) using the criteria described in the methods section. Any participant displaying a positive result by any of the screening tests was considered seropositive. A large proportion of hospitalised patients (82\%) presented a clinical score of 4 (Severe Pneumonia) (Table 1B). Approximately half of these patients (47\%) presented septic shock or sepsis (clinical scores of 7 and 6), $38 \%$ developed ARDS (Acute Respiratory Distress Syndrome) or severe pneumonia (clinical score 5 and 4) and only two patients presented moderate pneumonia (clinical score 3). Only two patients were asymptomatic. All patients (but not all HCW) had a positive PCR diagnostic result and all patients, except two, presented SARS$\mathrm{CoV}$-2-specific antibodies. Clinical scores of seropositive HCW ranged between 1 and 3. A third of these individuals (33\%) presented moderate pneumonia (clinical score of 3), 50\% showed mild disease (clinical score 2 ) and $12.5 \%$ were asymptomatic. In contrast, the majority of seronegative HCW were asymptomatic (59\%) or presented with symptoms of mild disease (33\%) and only 3 individuals presented moderate pneumonia.

\subsection{Calibration and Standardisation of Antibody Assays}

Whenever possible, we defined candidate humoral CoP in units relative to the WHO International Standard. Quantitative antibody assays (pMN, RBD ELISA, N ELISA) were calibrated using our internal reference antiserum (HICC S2) or an external 
calibrant. At the start of this work, the WHO International Standard, NIBSC 20/136 had not yet been developed and we calibrated our internal standard against the NIBSC 20/162 calibrant reagent, which was available at that time. In some instances, we used the latter reagent directly as our assay calibrant in the neutralisation $(\mathrm{nAb})$ assay. This reagent, NIBSC 20/162, was assigned 1000 units for the pMN, the panIg $\mathrm{N}$ and the pan-Ig $\mathrm{S}$ assays. The results of the pMN, N-ELISA and RBD-ELISA, were converted to IU or Binding Antibody Units (BAU) of the WHO International Standard (NIBSC 20/ 136) once the latter became available.

In order to calculate the Unitage of the HICC reference sera (used as Internal Calibrants), we tested in the same assay serial dilutions of the HICC reference sera and NIBSC reagents. After preparing the corresponding calibration curves (Figure 1), we performed a parallel line analysis. Such analysis supported the mathematical derivation of a unitage value for our internal calibrants from the NIBSC 20/162 reagent. Thus, HICC Serum-2 was assigned a value of $504 \mathrm{BAU} / \mathrm{ml}$ for the pan Ig $\mathrm{N}$-ELISA, $98 \mathrm{BAU} / \mathrm{ml}$ for the pan Ig-G RBD ELISA and $76 \mathrm{IU} / \mathrm{ml}$ for the pMN assay. The results of each sample tested by these assays were expressed in the corresponding units as follows:

$$
\begin{aligned}
\text { Units of sample }= & \left(\mathrm{IC}_{50} \text { of Test sample } / \mathrm{IC}_{50} \text { of calibrant }\right) \\
& \times \text { unitage of the calibrant }
\end{aligned}
$$

When the WHO International Standard for anti-SARS-CoV-2 immunoglobulin 20/136 became available, the conversion into International Units (IU) and Antibody Binding Units (BAU) specific for N-, RBD-, and S- antigens (N-BAU,RBD-BAU, SBAU) was calculated by multiplying the values (units) of samples by a factor $\mathrm{F}$, which is the ratio of the $\mathrm{IC}_{50}$ of NIBSC 20/162 relative to the $\mathrm{IC}_{50}$ of the International Standard 20/136. Thus, all results of the pMN and the Pan-Ig ELISA tests included in this study are expressed in IU and BAU relative to the $\mathrm{WHO}$ International Standard, respectively.

\subsection{Antibody Biomarkers of COVID-19 Immunity as Potential CoP}

The convalescent serum or plasma samples from these three cohorts were analysed by a range of assays that measure antibody-based biomarkers of immunity: a) a pseudotypebased microneutralisation assay (pMN); b) a Luminex IgG assay specific for N, S and RBD; c) a pan-Ig ELISA for $\mathrm{N}$ and RBD; d) a multiplex antigen (S, S1, S2, N and RBD) immunoblotting assay for IgG, IgM and IgA; e) a commercial lateral flow assay for rapid detection of SARS-CoV-2-specific IgG and IgM; and f) a commercial electrochemiluminescence assay (ECLIA).

We analysed the data of all these assays and determined individual correlations of all these measurements with one another and with the clinical severity scores assigned to the individuals the samples derived from. These analyses (Figure 2A) showed four main clusters of assay correlations. The first cluster is represented by IgA Immunoblotting assays for S, S1, S2 and RBD (Figure 2B). A second group is formed by IgG assays based on Spike-derived antigens and pMN assay (Figure 2B). The third cluster is formed by $\mathrm{N}$-specific assays (Figure 2C). The intracellular neutralisation assay (EDNA) correlated positively with $\mathrm{N}$-specific IgG and IgA binding assays. Due to the shorter duration of IgM than IgG and IgA in blood following a viral infection, it was not surprising that the IgM assay results of convalescent sera did not show positive or negative correlations with the IgG, IgA, pMN assays, intracellular neutralisation or clinical severity. Overall, clinical severity correlated positively with $\mathrm{nAb}$ data, S/RBD, $\mathrm{N}$ antibody binding measurements. As expected, $\mathrm{nAb}$ data correlated more strongly with S-specific and RBD-specific binding antibodies than with $\mathrm{N}$-specific antibody levels, indicating $\mathrm{N}$-specific antibodies maybe a good biomarker of previous infection and its severity but not necessarily the best surrogate of nAb.

Having established the general correlations of the biomarkers under study in these convalescent samples, we dissected in more detail the data generated by these assays.
A

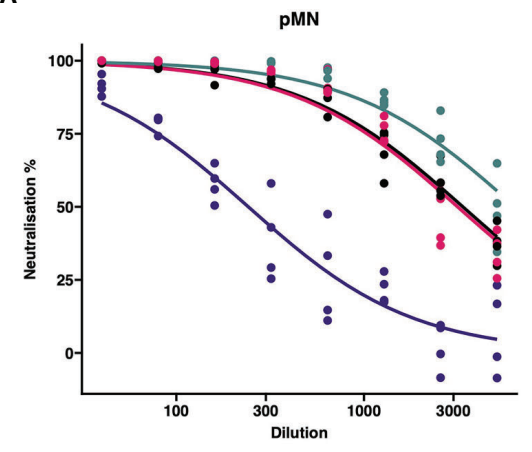

B

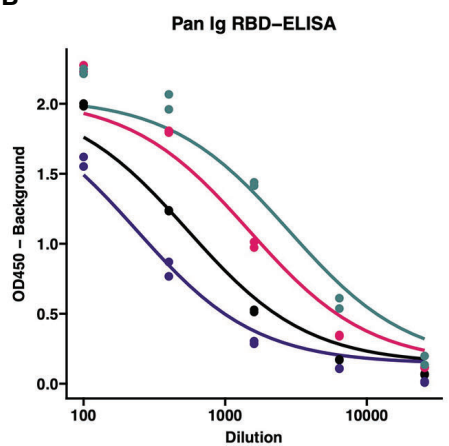

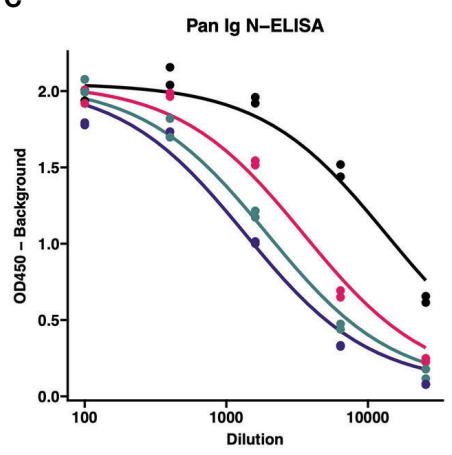

FIGURE 1 | Comparison of internal calibrants and International Standard for neutralization and binding assays. The IC $_{50}$ from these curves were used to calculate the (A) International units (IU); (B) RBD-specific Binding Antibody Units (BAU); and (C) N-specific Binding Antibody Units (BAU). Calibrants were run four times at each dilution for pMN and twice for ELISA tests. 


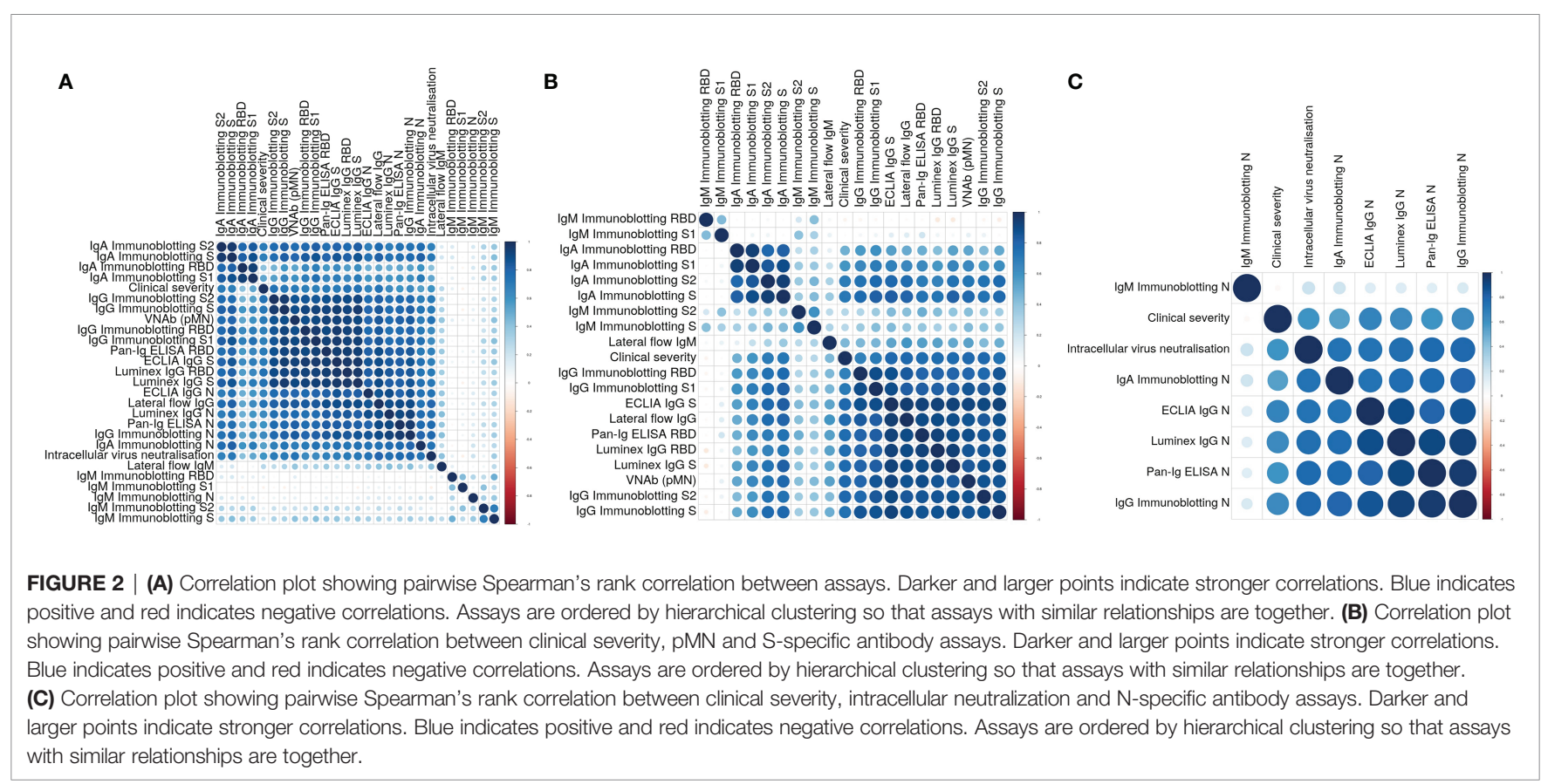

\subsection{SARS-CoV-2 Antigen Specific Antibody Responses}

The antibody screening assays used to classify the serum samples from patients and HCW produced concordant results with a few exceptions. All samples from patients were positive by all three IgG assays except those from patient 37 and patient 50 , which tested negative by all three assays. These patients were asymptomatic and their clinical histories revealed that they were already hospitalised for other conditions before becoming infected with SARS-CoV-2. Only a small group of seropositive HCW samples produced discordant results. Thus, HCW s198, s223, s286, s370, s398 and $s 423$ presented positive results only by some of the assays but none of these results were strongly positive. As expected, a proportion of the convalescent samples from patients and HCW did not test positive by the IgM lateral flow assay (data not shown).

The samples were classified into the three cohorts by the screening assays were analysed by the 'HICC in-house' pan-Ig ELISA for RBD and $\mathrm{N}$ antigens. The results were largely consistent with those of the Luminex, lateral flow assay and ECLIA tests. Only a few discrepancies were noted. Thus, all seronegative HCW samples tested negative by the N and RBD pan-Ig ELISA, except s195, s296 and s269 samples. HCW samples s195 and s196 were positive for RBD, presenting values of 4.4 and 2.5 RBD-BAU/ml respectively, just above the negative cut-off value (2 RBD-BAU/ml), but were negative by the N ELISA (negative cut-off value of $4 \mathrm{~N}-\mathrm{BAU} / \mathrm{ml})$. Sample s269 which had $14.3 \mathrm{~N}$ $\mathrm{BAU} / \mathrm{ml}$ (negative cut-off value $7.7 \mathrm{~N}-\mathrm{BAU} / \mathrm{ml}$ ) but was negative for RBD. As expected, all patients' samples tested positive against both antigens and presented high values (mean 414.5 RBD-BAU/ $\mathrm{ml}$; mean $316 \mathrm{~N}-\mathrm{BAU} / \mathrm{ml}$ ), except patient 37, which tested negative for both antigens. Patient 50, which tested negative by all screening serological assays, presented low antibodies to RBD
(20.9 N-BAU/ml) and N (26.3 N-BAU/ml) antigens. Results of the pan-Ig N and pan-Ig RBD from seropositive HCW were also in line with the Luminex, lateral flow and ECLIA tests. The average antibody levels of seropositive HCW, 118.9 RBD-BAU/ $\mathrm{ml}$ and $234.6 \mathrm{~N}-\mathrm{BAU} / \mathrm{ml}$, were significantly lower than those found in patients (Mann-Whitney U test, RBD: $U=717, p<0.001$; $\mathrm{N} \mathrm{U}=630, \mathrm{p}=0.006$ ). The same samples that produced conflicting results by the serological screening assays, namely s198, s223, s286, s370, s398 and s423, produced very low $\mathrm{N}$ - and RBDBAU results.

\subsection{Virus Neutralising Antibody Responses Measured by Pseudotype Based Micro- Neutralisation}

The pMN results revealed a significant difference in neutralising antibody titres (nAb) between the three cohorts (Figure 3). As expected, the seronegative HCW sera presented very low nAb (mean $5.3 \mathrm{IU} / \mathrm{ml}$ ). In contrast, seropositive HCW presented moderately high nAb levels (mean value $379 \mathrm{IU} / \mathrm{ml}$ ), whereas patients presented a three-fold higher level $(1029 \mathrm{IU} / \mathrm{ml})$. Of note is that three seronegative HCW $(\mathrm{s} 38.2, \mathrm{~s} 38.1, \mathrm{~s} 228)$ had low $\mathrm{nAb}$ but these were above $24.2 \mathrm{IU} / \mathrm{ml}$ (mean of negative HCW+ 2STD). This pMN value is well above $6 \mathrm{IU} / \mathrm{ml}$, a negative cut-off value for this assay calculated from a small panel of prepandemic sera (mean $+2 \mathrm{SD}$ ) suggesting that these individuals could have been exposed to SARS-CoV-2, despite antibody binding assays showing negative values for all of them. Five seropositive HCW samples (s223, s286, s370, s398 and s423) had $\mathrm{nAb}$ below $6 \mathrm{IU} / \mathrm{ml}$, which was consistent with the low values obtained in the serology screening tests and the pan-Ig ELISA. All of these individuals were asymptomatic or had mild disease without pneumonia, except HCW 370 who had moderate pneumonia. It would be interesting to investigate the frequency 


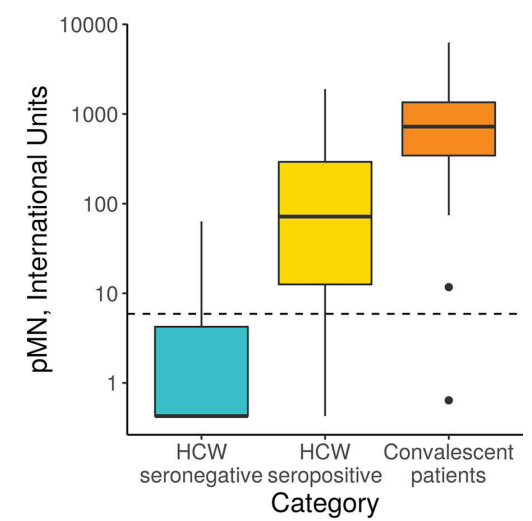

B

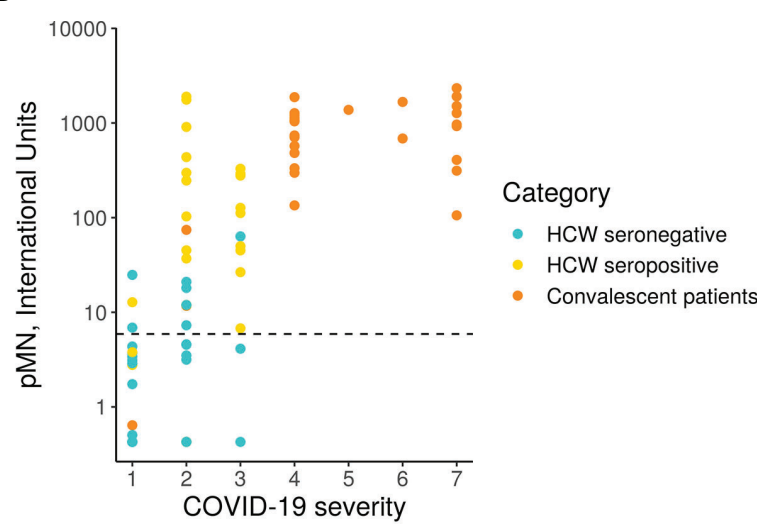

FIGURE 3 | pMN virus neutralisation in International Units by cohort and COVID-19 severity. (A) Boxplot showing the difference between cohorts. (B) Scatterplot showing neutralisation against disease severity. The dotted line shows the 95\% upper Cl calculated from pre-pandemic sera, 5.9 International Units.

of these cases and understand the biological meaning of these results in these particular individuals.

A more detailed analysis of the data revealed a very strong correlation between clinical severity score and $\mathrm{nAb}$ (Figure 3, Spearman's rank correlation $=0.71$ ). As previously indicated in Section 3.1, the majority of hospitalised patients (clinical scores $>4$ ) presented very high nAb levels, the majority above $200 \mathrm{IU} / \mathrm{ml}$, and in some cases reached values as high as $2117 \mathrm{IU} / \mathrm{ml}$. However, two patients' samples, those from patients, 37 and 50, had levels of nAb as low as 0.63 and $11 \mathrm{IU} / \mathrm{ml}$ respectively. These samples also had low values in the ELISA and Luminex assay as discussed in the previous section. Patient 17 presented low antibody levels by both assays but remain above the positive threshold and consistent with this, presented moderate $\mathrm{nAb}$ levels $(74 \mathrm{IU} / \mathrm{ml})$. Consistent with the correlation observed between severity and nAb levels, patients 17, 37 and 50 had clinical scores of 1 and 2 .

The $\mathrm{nAb}$ data distribution in infected HCW is more widespread, ranging between 0.426 to $2092 \mathrm{IU} / \mathrm{ml}$, including asymptomatic cases of COVID-19 (clinical score of 1) to moderate pneumonia with $\mathrm{Sp}>90 \%$ (clinical score of 3 ). Some of the samples had nAb levels as high as those observed in most severe cases of COVID-19. As expected, the seronegative group of $\mathrm{HCW}$ presented very low $\mathrm{nAb}$ levels ranging between 0.426 to $18 \mathrm{IU} / \mathrm{ml}$ with clinical scores of 1 or 2 .

\subsection{SARS-CoV-2 Antigen Display by Automated Microfluidics Western Blot Analysis}

In order to dissect the specificity of the antibody response to Spike (S) and nucleoprotein (N) of SARS-CoV-2 and to identify additional candidate biomarkers of immunity, we used a semiautomated immunoblotting assay (Jess, Protein Simple, Biotechne) based on the separation of protein antigens in a polyacrylamide gel matrix contained in a capillary tube. This microfluidics assay sequentially processed diluted plasma samples, conjugated antibodies, washing buffers and chemiluminescent reagents sequentially through microfluidics. A final chemiluminescent reaction is read by the device and translated into a luminometry intensity signal which can be analysed quantitatively. The results are visualised as traditional western blotting lane format or analytically the data outputs as densitometric units for quantitative antigen specific responses. We utilised this assay qualitatively (immunoblotting images) and quantitatively (using total luminometry units) to screen and confirm antibody specific responses to the intact Spike protein and its subunits, S1, S2, and RBD as well as the SARS-CoV$2 \mathrm{~N}$ antigens. Furthermore, antibody isotype (IgM, IgG, and $\operatorname{IgA}$ ) and IgG subtype responses (IgG1 to 4) were measured.

\subsubsection{Quantitative Data}

The results of IgG responses (Figure 4) were consistent with the findings described above for the antigen binding assays (Luminex, Lateral Flow, ECLIA and ELISA assays). The IgG antibody responses of COVID-19 patients showed significantly higher median Chemiluminescent Intensity Units (CIU) values than those of seropositive HCWs. Of note is the wide range of $\mathrm{N}$ specific and S-specific IgG CI measurements, of both patients and seropositive HCW.

For the most part, the results of the IgA antibody immunoblotting mirrored those of the IgG responses although the median CIU was significantly lower than for IgG, with values below 10,000 $\mathrm{CIU}$ as opposed to the IgG values for the same antigen in the range of 300,000 CIU. The IgA responses to the Spike subunits, RBD, S1 and S2 of seropositive HCWs against $\mathrm{N}$ and Spike were markedly lower than those exhibited by the IgG responses while not surprisingly, IgM responses were heterogeneous in this crosssectional convalescent study, presenting negative or close to ' 0 ' median CIU values for all three cohorts against all five antigens. Although the time of sampling was approximately 3-5 months following exposure or hospitalisation, IgM was clearly detected in a very few individuals.

\subsubsection{Qualitative Data - Antigenic Specificity of the Antibody Response}

Analysis of the immuno-blotting electropherograms revealed that the relative antigen response of individual sera was 


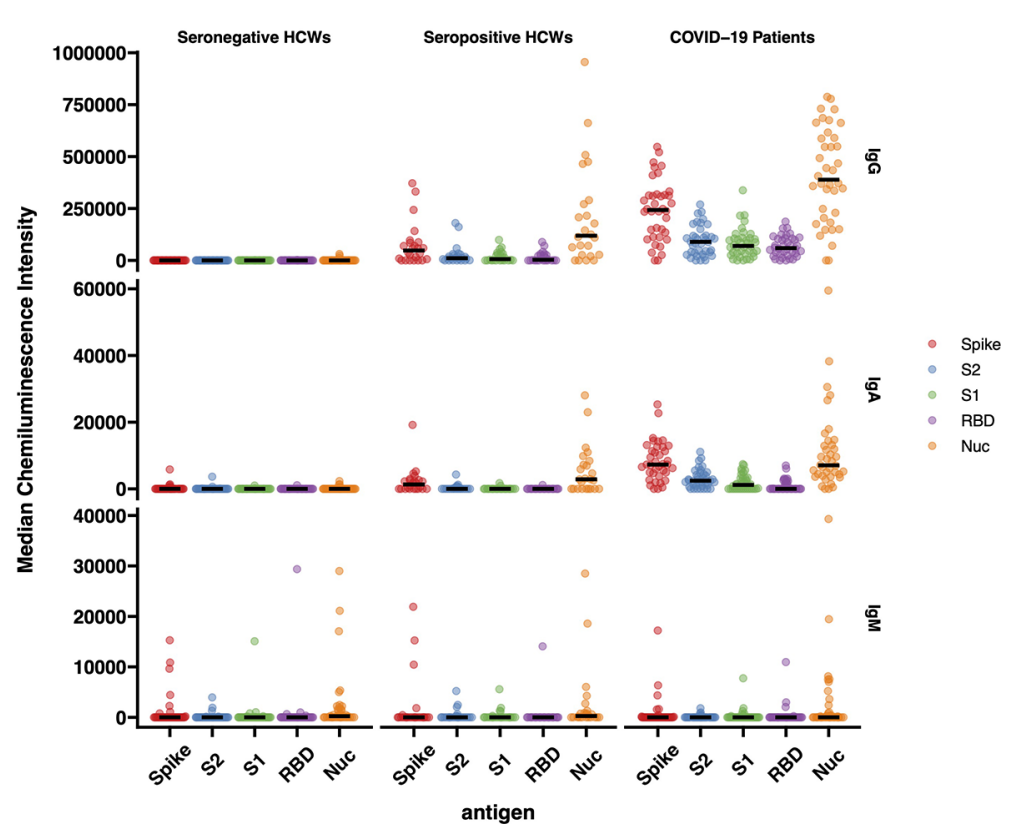

FIGURE 4 | IgG, IgA and IgM responses against Spike, RBD, S1, S2 and N antigens of SARS-CoV-2. The image displays the Median Chemiluminescence Intensities of antigen-specific IgG (top), IgA (middle) and IgM (bottom) of seronegative HCWs (left), seropositive HCWs (middle) and COVID-19 patients (right). A panel of pre-pandemic sera was used to calculate the negative cut-off value for each antigen (mean + 2STD) and then subtracted from the chemiluminescent signal of each sample.

heterogeneous across patients and seropositive HCW revealing four distinct patterns of antigen specific responses. Representative results of these patterns are presented in Figure 5. Most patients' samples showed equally strong IgG reactivities against both $\mathrm{N}$ and $\mathrm{S}$ antigens (High $\mathrm{N}=\mathrm{S}$ ). However, a number of samples displayed weaker signals against both antigens (patients p17, p37, p50) (Low $\mathrm{N}=\mathrm{S}$ ), whereas some presented predominantly an anti-N reactivity (p40) $(\mathrm{N}>\mathrm{S})$ and some had predominantly anti-S-specific antibodies (p8) $(\mathrm{N}<\mathrm{S})$ (Figure 3B). This heterogeneity of the antigen specificity of the IgG response was also evident in the results of seropositive HCW samples. Again, these four categories could be distinguished according to N/S ratios: a) $\mathrm{N}=\mathrm{S}$ (high) (HCW 361.1); b) N > S (HCWs s24.1, s25.1, s38.1, s38.2, s117.1, s224.1, s414); c) $\mathrm{N}<\mathrm{S}$ (HCWs s249.1, s408) and d) $\mathrm{N}=\mathrm{S}$ (low) (HCWs s4.1, s198.1, s223.1, 254.1, s286.1, s418.1, s423.1, s439.1). Similarly, these patterns were also identified in the IgA responses, although uniformly lower than the IgG responses in all individuals, especially in the seropositive HCW.

There were very few samples giving a positive result in the IgM immuno-blotting assay and this signal was very low in magnitude except for one sample in each of the cohorts. For this reason the antigenic specificity patterns of the IgM response differed significantly from the IgG and IgA responses. Most positive IgM samples in the patient cohort were $\mathrm{N}$-specific $(n=7)$, albeit the detection signal of the electropherogram was weak in 6 of them, and only one of the samples also had an S-specific IgM signal. Some of the seropositive HCW samples detected the Spike (s25.1, s308.1 and s398.1) and its subunits RBD, S1, S2 (s398) as well as N (s398 and s418). One sample presented a strong $\mathrm{N}$ response (HCW s418) suggestive of a recent exposure to SARS-CoV-2 or to a common cold coronavirus which was not detected by the primary screening serological tests used in this study.

\subsection{Intracellular Neutralisation Assay (EDNA)}

To explore the potential use of biomarkers indicative of TRIM21 based mechanisms of immunity we applied the EDNA assay to our cohorts' samples. We electroporated Vero ACE2/ TMPRSS2 cells with sera from each patient and seropositive HCW and ten seronegative HCW samples for reference. In the presence of electroporated $\mathrm{N}$-binding antibodies, virus replication was inhibited. The results of these analyses (Figure 6) indicate that patients' sera are more effective at inhibiting virus replication than sera from the seropositive HCW. All but one patients' samples were positive by the EDNA (Figure 6B). In contrast, some seropositive HCW tested negative or produced a low positive result (Figure 6C), whereas all tested seronegative HCW did not affect virus replication, as expected (Figure 6D). Interestingly, patients and seropositive HCW samples with the strongest inhibition of virus replication had the highest levels of anti- $\mathrm{N}$ antibodies such as s414 or p32, confirming that the observed intracellular neutralisation is mediated by anti- $\mathrm{N}$ antibodies. Importantly, these results highlight that traditional neutralization assays, fail to measure the potential contribution of anti- $\mathrm{N}$ antibodies present in SARS-CoV-2 positive sera. 
A

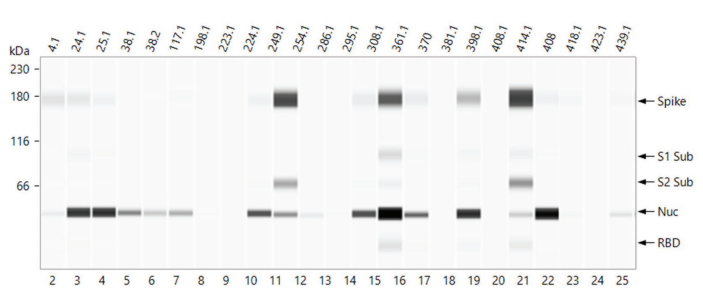

B

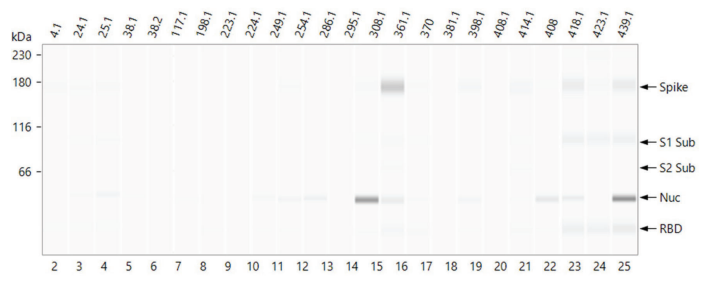

C

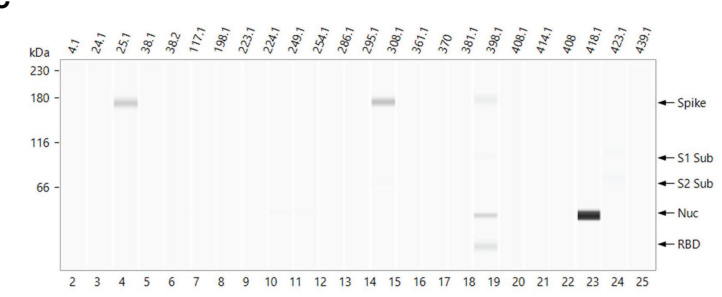

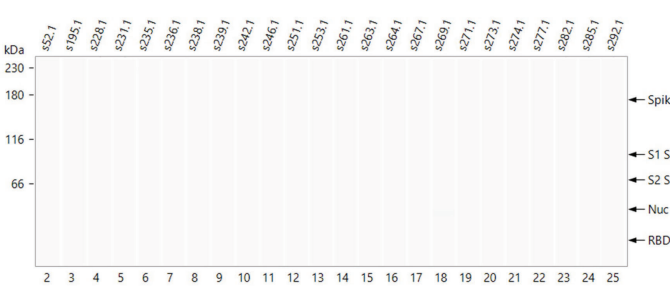

E

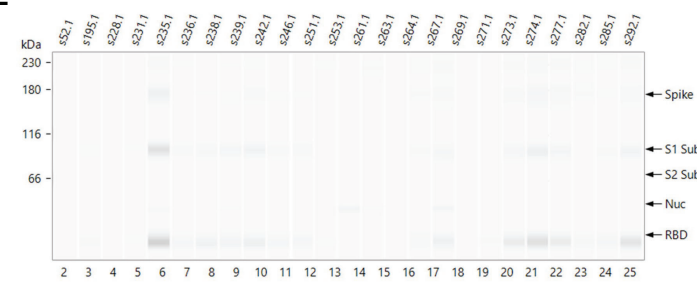

$\mathbf{F}$

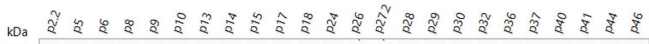

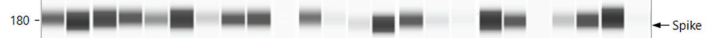
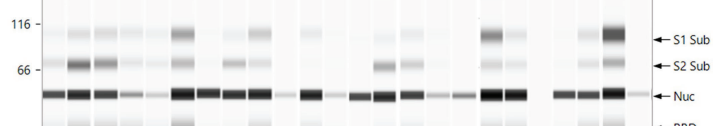

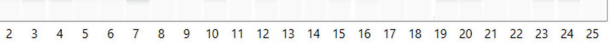

H

Patient (IgA)

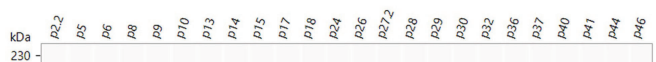

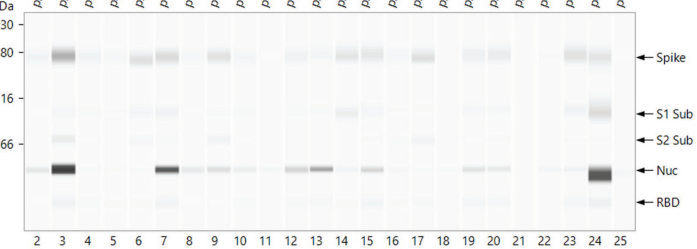

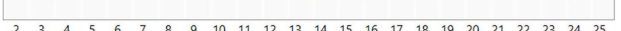

Patient (IgM)

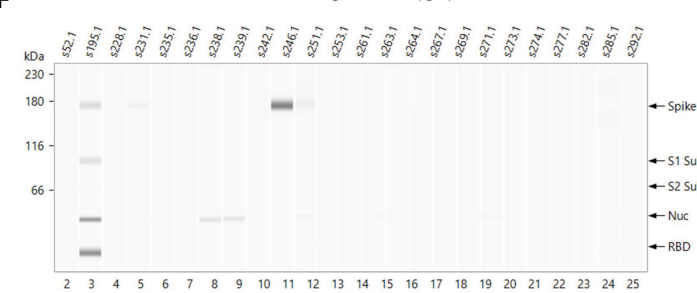

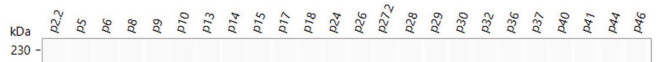

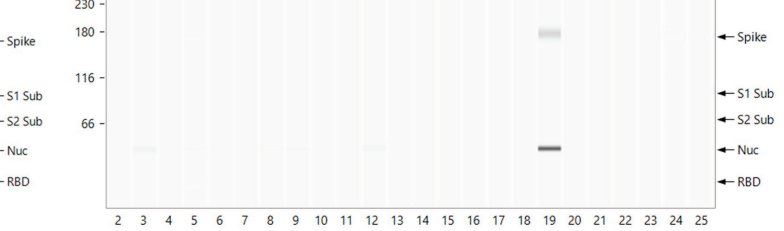

FIGURE 5 | Representative electropherograms of IgG, IgA and IgM antibody responses to Spike, RBD, S1, S2 and N antigens of SARS-CoV-2 in Health Care Workers and Patients. Thefigure shows antigenspecific IgG (A, D, G), IgA (B, E, H) and IgM (C, F, I) antibody reactivities of seropositive HCWs (left panel), serongative HCWs (middle panel), and patients (right panel). 
A

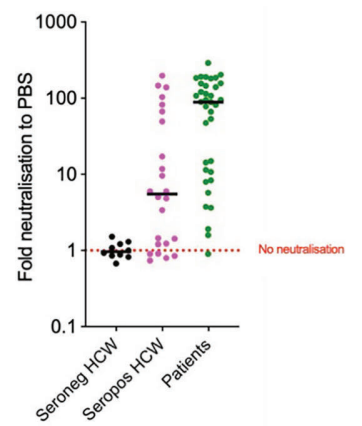

C

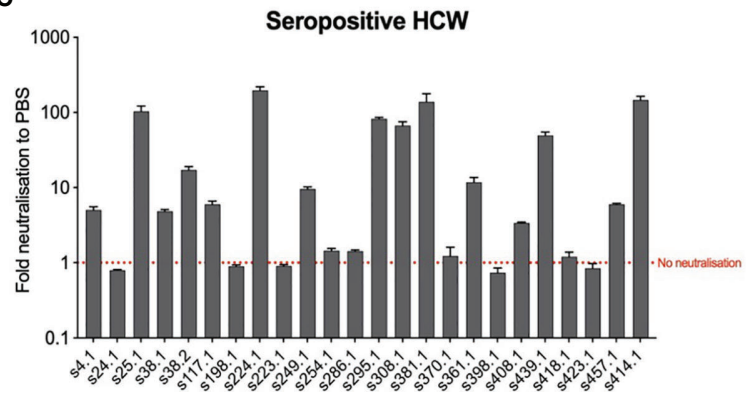

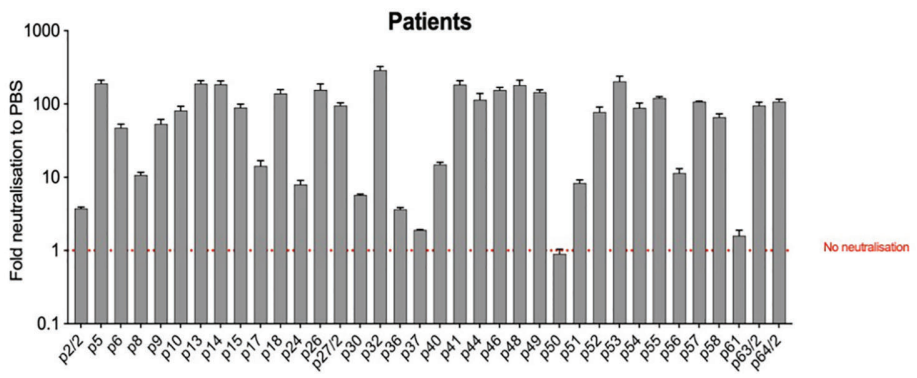

D

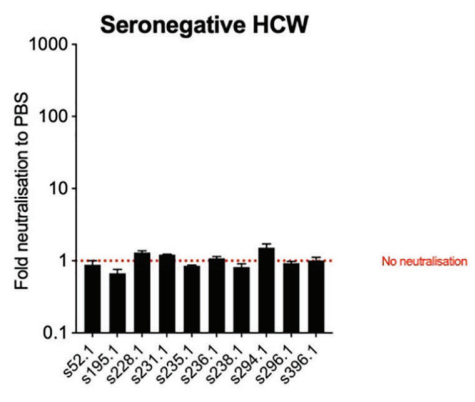

FIGURE 6 | Intracellular neutralisation data from EDNA assay. The results are expressed in genome copies relative to 18S and percentage normalised to PBS. Panel (A) depicts median values of EDNA results of the three cohorts, expressed as Fold neutralisation relative to PBS; Panels (B-D) correspond to individual EDNA results of patients, seropositive HCW and seronegative HCW respectively.

\section{DISCUSSION}

The 'Humoral Immune Correlates of COVID-19 Project (HICC)' (https://www.hicc-consortium.com/) was established to identify humoral biomarkers of immunity and develop standardised assays to determine the thresholds of antibody responses that correlated with protection against SARS-CoV-2 infection or with severe COVID-19 disease requiring hospitalisation. Before conducting serological analysis of vaccine breakthrough or reinfection cases with which to define correlates of protection we wanted to define first those candidate antibody biomarkers by cross-platform comparison of a range of antibody-based assays, such as nAb and SARS-CoV-2 antigen-specific (N-, S-, S1S2- N- and RBD) binding antibodies (Pan-Ig, IgG, IgM, IgA) in convalescent serum or plasma samples from COVID-19 hospitalised patients and seropositive and seronegative HCW (Table 3). The main findings of the present study confirmed: a) that there is a strong positive correlation between clinical severity and SARS-CoV-2-specific antibodies; b) that there is a strong correlation between $\mathrm{nAb}$ and $\mathrm{S}$ - and RBD-specific antibody levels; c) that intracellular neutralisation correlated very well with $\mathrm{N}$-specific antibody levels; and d) that there are different antigen-specific reactivity patterns of IgG, IgA and IgM in seropositive samples. We used the WHO International Standard (NIBSC 20/136) to quantify some of these antibodybased parameters in International Units (IU) for neutralisation assays and Binding Antibody Units (BAU) for ELISA. The adoption of common results reporting unitage in IU and BAU as those described in this study would eventually facilitate comparative analyses of data generated by immunogenicity studies performed by different teams in different parts of the world.

The criteria for the serological classification of the convalescent samples used in this study were based on a UKAS-accredited Luminex assay benchmarked for COVID serological screening (33) and another two well-stablished serological assays (AccuTell lateral flow IgG/IgM; Roche ECLIA) (30, 40, 41). The results of these tests were consistent with other additional tests (pan-Ig N and RBD ELISA; immuno-blotting) described in this paper. As expected, only samples with low antibody levels produced some discrepancies due to the positive-negative cut-off of each particular assay. Such discrepancies could also be due to the previously described cross-reactivity between the $\mathrm{N}$ antigens of SARS-CoV-2 and the seasonal human common cold coronaviruses (42) which was also consistent with our analysis of pre-pandemic serum samples.

Consistent with published data $(8,11,43,44)$, we found a very strong correlation between $\mathrm{nAb}$, as measured by the $\mathrm{pMN}$ assay, and severity of disease. Evidence from epidemiological studies and vaccine clinical trials indicated that $\mathrm{nAb}$ correlate with immunity against COVID-19 $(45,46)$. However, knowledge of the early immunopathologic events that trigger severe COVID-19 disease is still incomplete, in particular the role of complement system its interaction with early antibody responses.

Various studies indicate that the high nAb levels found in severe COVID-19 patients are a consequence of the high and 
TABLE 3 | Summary of the main features of the antibody-based assays used in this study.

\begin{tabular}{|c|c|c|c|c|c|c|}
\hline Antibody assays & $\begin{array}{l}\text { Isotype/ } \\
\text { Sub-isotype }\end{array}$ & Functional & Turnaround & Throughput & $\begin{array}{l}\text { Suitable for Standardisation } \\
\text { (WHO Standard) }\end{array}$ & $\begin{array}{l}\text { Potential to derive a } \\
\text { Correlate of Protection }\end{array}$ \\
\hline Pan Ig ELISA - N & $\lg G+\lg A+\lg M$ & No & 24 hours & Medium & Yes & Unknown \\
\hline Pan Ig ELISA - S & $\lg G+\lg A+\lg M$ & No & 24 hours & Medium & Yes & Possible \\
\hline ECLIA (total Antibody) - N & $\lg G+\lg A+\lg M$ & No & 24 hours & $\begin{array}{l}\text { Medium- } \\
\text { High }\end{array}$ & Likely & Unknown \\
\hline ECLIA (total antibody) - S & $\lg G+\lg A+\lg M$ & No & 24 hours & $\begin{array}{l}\text { Medium- } \\
\text { High }\end{array}$ & Likely & Possible \\
\hline $\begin{array}{l}\text { Multiplexed Bead Flow Cytometry - } \\
\text { Luminex (IgG/IgA/lgM) }\end{array}$ & $\operatorname{lgG} / \lg A / \lg M$ & No & 6 hours & $\begin{array}{l}\text { Medium- } \\
\text { High }\end{array}$ & Potentially & Possible \\
\hline Semi-automated Immunoblotting & $\lg G / \lg A / \lg M$ & No & 4 hours & $\begin{array}{l}\text { Medium- } \\
\text { High }\end{array}$ & Potentially & Possible \\
\hline Lateral Flow IgG/lgM & $\lg G / \lg M$ & No & 30 mins & Low & No & No \\
\hline EDNA & N/A & $\begin{array}{l}\text { Yes; TRIM-21 } \\
\text { mediated CTL }\end{array}$ & 48 hours & Low & Not possible at the moment & Unknown \\
\hline pMN & $\mathrm{N} / \mathrm{A}$ & $\begin{array}{l}\text { Yes; Virus } \\
\text { neutralisation }\end{array}$ & 48 hours & Low & Yes & Reasonably likely \\
\hline
\end{tabular}

$\lg \mathrm{G}+\lg A+\lg M$, indicates the three isotypes are detected simultaneously in the assay. $\lg \mathrm{G} / \mathrm{lg} A / \lg M$, indicates that each isotype generates a separate reading.

persistent viral replication, high virus load and that the marked expression of viral antigens in the host, or alternatively, a consequence of a dysregulated immune response leading to antibody-mediated immunopathology. Studies by GarciaBeltran and co-workers suggested the latter and that the antibody response profile in severe patients, characterised by high $\mathrm{nAb}$ to IgG-RBD ratios, is a consequence of such dysregulation. These authors suggested that the use of specific antibody response metrics could be useful to discriminate between immuno-pathological antibody responses from those that would lead to protective immunity. Our study does not address this question but proposes different antibody-based assays, parameters and standardised methods that could facilitate comparative data analysis of humoral immunity. Use of these antibody response metrics could be applied to serum or plasma samples in vaccination efficacy/efficiency or re-infection studies in order to elucidate thresholds of protective immunity.

COVID-19 serological studies published to date show a positive correlation between Spike-specific antibodies and nAb (47). Accordingly, our study showed that nAb of COVID-19 convalescent sera correlated very strongly with Spike-specific IgG and IgA binding antibodies. This can be potentially very advantageous for assessing protective immunity in clinical trials or in immuno-surveillance programmes, as evidence supporting the use of $\mathrm{nAb}$ as a biomarker of COVID-19 immunity continues to grow (48). Indeed, some of the S-specific antibody binding assays used in our study are quantitative, reproducible, suitable for calibration to the international standard and highthroughput. The latter is a distinct advantage over the more laborious and time-consuming neutralisation assays. However, validity of these correlations need further evaluation as other reports indicate the importance of $\operatorname{IgM}$ and $\operatorname{IgA}$ contribution to virus neutralisation, and that the $\mathrm{nAb} / \mathrm{IgG}$ ratio correlate with 30-day survival (11).

Our data also showed a strong correlation between nAb, disease severity and N-specific IgG and IgA antibody levels in convalescent samples. The intracellular neutralisation data generated by the EDNA assay represents an indirect evidence that the TRIM-21 mediated mechanism of immunity could play a relevant role in protection against COVID-19. The output of the EDNA assay from SARS-CoV-2 infected cells previously electroporated with serum from patients or HCW showed a significant reduction of virus replication. This was proportional to the N-specific antibody levels of the sera. Previously, it has been shown that antibody-antigen complexes are rapidly degraded in the cytosol by TRIM21 and the proteasome (17, 49). If $\mathrm{N}$ protein is degraded inside an antigen presenting cell, this provides peptides for MHC-I presentation. Indeed, studies have shown that cytotoxic T-cell immunity to virally-infected cells requires internalization and cross-presentation of virusantibody complexes by dendritic cells (50). It has been previously shown that TRIM21 uses anti-N antibodies to degrade the nucleoprotein of LCMV, promote cytotoxic T-cells and clear mice of infection (18). As indicated earlier, longitudinal analyses of antibody levels from patients and HCW will help to determine the relevance of this anti-SARS-CoV-2 immunity mechanism and how $\mathrm{N}$-specific antibodies might contribute to either protective immunity or immuno-pathology. Here we provided experimental evidence that sera from COVID-19 convalescent patients and seropositive HCW, but not those from seronegative HCW, neutralised effectively SARS-CoV-2's infectivity intracellularly and that these measurements correlated very strongly with anti-N antibody levels (Figure 2).

The analysis of the antigen specificity of serum IgG and IgA of patients and HCW showed an overall immuno-dominance of $\mathrm{N}$ and S-specific antibodies over S1, S2 and RBD antigens. However, we observed, consistent with other studies (51), that the N/S ratios were not always homogeneous. Further analyses of the evolution of antigen-specific antibody responses of our cohorts over time will help to interpret the relationships between these metrics and the clinical outcome of SARS-CoV2 infection.

Our data indicate that serum IgA responses paralleled those of IgG in terms of antigen specificity, albeit the magnitude is 
significantly lower. Mucosal IgA might represent a critical component of the immune response against COVID-19 $(52,53)$ as it contributes to virus neutralisation (54). Interestingly, studies have stablished a correlation between serum IgA levels and severity, with mild COVID-19 cases, such as those occurring in the young, showing secretory IgA responses with little detection of IgA in serum (55). In our study we have found IgA in convalescent samples collected 3-5 months post-infection but consistent with Sterlin's findings (54) the levels were significantly reduced relative to IgG titres. However, Varadhachary and co-workers (53) have detected peak IgA levels in saliva at 3 months postinfection suggesting the kinetics of IgA in serum and mucosal surfaces are different. In our study we did not measure mucosal IgA and thus we were unable to establish their correlation with serum IgA but further efforts should be aimed at elucidating how these two isotypes evolve in time in different body compartments in order to define an IgA-based biomarker of protection.

After a viral infection, IgM responses are usually the first to appear in serum and this is the case too for COVID-19 $(56,57)$. Our data indicates that IgM are easily detected only in a few individuals from the patients and seropositive HCW cohorts. Some studies report IgM lasting up to at least 3 months postinfection $(56,58)$ and it is therefore not surprising that IgM was detected in some of our convalescent samples.

A cornerstone of our study was the use of the WHO International Standard for anti-SARS-CoV-2 immunoglobulin (20/136) to benchmark neutralising antibody responses and to relate other binding assays to our findings with this standard. We expressed in International Units (IU) and Binding Antibody Units (BAU) the results of the most commonly used serological assays (25). The objective of this approach was to adopt the WHO International Standard unitage to quantify the levels of cardinal serological (antibody) biomarkers of COVID-19 immunity in order to facilitate cross-comparison of immunogenicity data, which ultimately will facilitate the derivation of Correlates of Protection against COVID-19. This may become increasingly important for bio-regulatory approval of SARS-CoV-2 vaccines in future months. Indeed, the emergence and rapid spread across the globe of COVID-19, prompted the rapid development of vaccines against this disease. However, the vast amount of scientific data arising from clinical trials and epidemiological studies addressing COVID-19 immunity have not yet translated into an unequivocal definition of a reliable $\mathrm{CoP}$. The vaccines that are now being used across the globe were licensed on the basis of vaccine efficacy data obtained in placebo controlled clinical trials. These are very costly and they depend on the rates of natural infections occurring in the populations to which the vaccinated participants belong. However, more vaccines are needed to meet the global public health demands, even more so with the emergence of SARS-CoV-2 variants of concern with proven ability to escape the antibody responses developed against vaccines or previous infections (https://www.sciencedirect.com/ science/article/pii/S0092867421002981). But the exposure of participants to natural infections in placebo-controlled clinical trials, are increasingly difficult to justify. Furthermore, recruitment of seronegative volunteers will become more and more complicated with the continuing rise of SARS-CoV-2 seroprevalence in the global human population. In these circumstances, non-inferiority clinical trial designs and immuno-bridging using an existing vaccine as a comparator would seem to be favoured. The definition of a CoP in International Units would help assess clinical efficacy of COVID-19 vaccines on the basis of analyses of immunogenicity data, rather than relying on evaluating clinical efficacy. Recent studies point to $\mathrm{nAb}$ as a reliable indicator of vaccine induced immunity (48). However, the majority of these studies used disparate assays and units to define antibody protection thresholds. The use of an International Unit for this purpose would enable comparative analyses of immunogenicity data to be made facilitating the derivation of CoP. It is important to note, that the WHO International Standard is not intended to be used as a day-to-day reagent, but rather, as a primary calibration reagent against which secondary standards should be calibrated. Thus, in our study, we calibrated our HICC sera against the WHO standard and used these HICC sera as our secondary calibration reagents to derive the unitage of the samples we tested in our assays.

In conclusion, we have identified a range of assays and biomarkers of COVID-19 immunity that will be used to define $\mathrm{CoP}$ in future studies using serum and plasma samples sequentially collected from these or similar cohorts, or notably, from vaccination breakthrough or re-infection cases. Such studies would need to extend their focus to SARS-COV-2 variants of concern that have been emerging since the beginning of the pandemic. The emergence of these strains with enhanced transmissibility, pathogenicity and antigenicity represents another challenge for vaccine manufacturers and regulators, and developing methods for standardising assays for comparison of Nab against VOC should be a priority.

\section{DATA AVAILABILITY STATEMENT}

The raw data supporting the conclusions of this article will be made available by the authors, without undue reservation.

\section{ETHICS STATEMENT}

Study approved by Research Ethics Committee Wales, IRAS: 96194 12/WA/0148. Amendment 5. The patients/participants provided their written informed consent to participate in this study.

\section{AUTHOR CONTRIBUTIONS}

JC-O: Coordinating the laboratory work; analysis of results; conception of the manuscript; writing the manuscript. DW: Statistical analysis. MF: Semiautomated immunology-blotting; analysis of results. AC: ELISA, Lateral flow testing; sample 
processing; analysis off results; PS: Blood processing, samples archiving, ELISA testing. AN: ELISA set up; pseudo neutralisation assay. MiP: Laboratory set up; ELISA set up. LO: Semi-automated immunoblotting. DC: pseudoneutralization assays. MMN: pseudoneutralization assay. PP: Statistical analysis. NJT: pseudoneutralization. DP: Design constructs, expression and purification of recombinant RBD. PN: Design constructs, expression and purification of recombinant RBD. RW: Design constructs, expression and purification of recombinant RBD. RD: Luminex assay. SK: Sample selection and provision prepandemic sera. AO: Electrochemiluminescence assays. AS: Electrochemiluminescence assays. AS: Electrochemiluminescence assays. TB: Electrochemiluminescence assays. AA: EDNA assay. LCJ: EDNA assay. MaP: Consultation on Standardization of serological assays. WS: Grant holder; assessing manuscript; scientific direction. HB: Clinical Lead; clinical assessment; coordination clinical work. JLH: Scientific direction. All authors contributed to the article and approved the submitted version.

\section{REFERENCES}

1. COVID-19 Public Health Emergency of International Concern (PHEIC) Global Research and Innovation Forum. Available at: https://www.who.int/publications/m/item/ covid-19-public-health-emergency-of-international-concern-(pheic)-globalresearch-and-innovation-forum (Accessed April 29, 2021).

2. Weekly Epidemiological Update on COVID-19 - 20 April 2021 (2021). Available at: https://www.who.int/publications/m/item/weekly-epidemiologicalupdate-on-covid-19-20-april-2021 (Accessed April 29, 2021).

3. Draft Landscape and Tracker of COVID-19 Candidate Vaccines. Available at: https://www.who.int/publications/m/item/draft-landscape-of-covid-19candidate-vaccines (Accessed April 29, 2021).

4. Tumban E. Lead SARS-CoV-2 Candidate Vaccines: Expectations From Phase III Trials and Recommendations Post-Vaccine Approval. Viruses (2020) 13:54. doi: 10.3390/v13010054

5. Focosi D, Maggi F. Neutralising Antibody Escape of SARS-CoV-2 Spike Protein: Risk Assessment for Antibody-Based Covid-19 Therapeutics and Vaccines. Rev Med Virol (2021), 1-17. doi: 10.1002/rmv.2231

6. Sui Y, Bekele Y, Berzofsky JA. Potential SARS-CoV-2 Immune Correlates of Protection in Infection and Vaccine Immunization. Pathogens (2021) 10. doi: 10.3390/pathogens10020138

7. Addetia A, Crawford KHD, Dingens A, Zhu H, Roychoudhury P, Huang ML, et al. Neutralizing Antibodies Correlate With Protection From SARS-CoV2 in Humans During a Fishery Vessel Outbreak With a High Attack Rate. J Clin Microbiol (2020) 58(11):e02107-20. doi: 10.1128/JCM.02107-20

8. Jeewandara C, Jayathilaka D, Gomes L, Wijewickrama A, Narangoda E, Idampitiya D, et al. SARS-CoV-2 Neutralizing Antibodies in Patients With Varying Severity of Acute COVID-19 Illness. Sci Rep (2021) 11:2062. doi: 10.1038/s41598-021-81629-2

9. Legros V, Denolly S, Vogrig M, Boson B, Siret E, Rigaill J, et al. A Longitudinal Study of SARS-CoV-2-Infected Patients Reveals a High Correlation Between Neutralizing Antibodies and COVID-19 Severity. Cell Mol Immunol (2021) 18:318-27. doi: 10.1038/s41423-020-00588-2

10. Rockstroh A, Wolf J, Fertey J, Kalbitz S, Schroth S, Lübbert C, et al. Correlation of Humoral Immune Responses to Different SARS-CoV-2 Antigens With Virus Neutralizing Antibodies and Symptomatic Severity in a German COVID-19 Cohort. Emerg Microbes Infect (2021) 10:774-81. doi: 10.1080/22221751.2021.1913973

11. Garcia-Beltran WF, Lam EC, Astudillo MG, Yang D, Miller TE, Feldman J, et al. COVID-19-Neutralizing Antibodies Predict Disease Severity and Survival. Cell (2021) 184:476-488.e11. doi: 10.1016/j.cell.2020.12.015

12. Lau EHY, Tsang OTY, Hui DSC, Kwan MYW, Chan W, Chiu SS, et al. Neutralizing Antibody Titres in SARS-CoV-2 Infections. Nat Commun (2021) 12:63. doi: 10.1038/s41467-020-20247-4

\section{FUNDING}

This study was undertaken by the Humoral Immune Correlates to COVID-19 (HICC) consortium, funded by the UKRI and NIHR; grant number G107217 (COV0170 - HICC: Humoral Immune Correlates for COVID-19). RW received funding from the StMWK (ForCOVID, Bavaria, Germany).

\section{ACKNOWLEDGMENTS}

We thank Dr John Briggs for supplying recombinant Spike protein used in the Luminex assays. We thank the RPH Foundation Trust COVID-19 Research and Clinical teams for supporting recruitment to this study, HCWs and Outpatients who participated in this study. MiP was supported by postdoctoral grants from Jane and Aatos Erkko Foundation, and Orion Research Foundation sr, Finland.

13. Trinite B, Tarrés-Freixas F, Rodon J, Pradenas E, Urrea V, Marfil S, et al. SARS-CoV-2 Infection Elicits a Rapid Neutralizing Antibody Response That Correlates With Disease Severity. Sci Rep (2021) 11:2608. doi: 10.1038/s41598021-81862-9

14. Mazzini L, Martinuzzi D, Hyseni I, Benincasa L, Molesti E, Casa E, et al. Comparative Analyses of SARS-CoV-2 Binding (IgG, IgM, IgA) and Neutralizing Antibodies From Human Serum Samples. J Immunol Methods (2021) 489:112937. doi: 10.1016/j.jim.2020.112937

15. Sedova ES, Scherbinin DN, Lysenko AA, Alekseeva SV, Artemova EA, Shmarov MM. Non-Neutralizing Antibodies Directed at Conservative Influenza Antigens. Acta Naturae (2019) 11:22-32. doi: 10.32607/20758251-2019-11-4-22-32

16. Earnest JT, Holmes AC, Basore K, Mack M, Fremont DH, Diamond MS. The Mechanistic Basis of Protection by non-Neutralizing Anti-Alphavirus Antibodies. Cell Rep (2021) 35:108962. doi: 10.1016/j.celrep.2021.108962

17. Mallery DL, McEwan WA, Bidgood SR, Towers GJ, Johnson CM, James LC. Antibodies Mediate Intracellular Immunity Through Tripartite MotifContaining 21 (TRIM21). Proc Natl Acad Sci U.S.A. (2010) 107:19985-90. doi: $10.1073 /$ pnas.1014074107

18. Caddy SL, Vaysburd M, Papa G, Wing M, O'Connell K, Stoycheva D, et al. Viral Nucleoprotein Antibodies Activate TRIM21 and Induce T Cell Immunity. EMBO J (2021) 40. doi: 10.15252/embj.2020106228

19. Albecka A, Clift D, Vaysburd M, Rhinesmith T, Caddy SL, Favara DM, et al. A Functional Assay for Serum Detection of Antibodies Against SARS-CoV-2 Nucleoprotein. EMBO J (2021) 40:e108588. doi: 10.15252/embj.2021108588

20. Galipeau Y, Greig M, Liu G, Driedger M, Langlois M-A. Humoral Responses and Serological Assays in SARS-CoV-2 Infections. Front Immunol (2020) 11:610688. doi: 10.3389/fimmu.2020.610688

21. Post N, Eddy D, Huntley C, van Schalkwyk MCI, Shrotri M, Leeman D, et al. Antibody Response to SARS-CoV-2 Infection in Humans: A Systematic Review. PloS One (2020) 15:1-27. doi: 10.1371/journal.pone.0244126

22. Espejo AP, Akgun Y, Al Mana AF, Tjendra Y, Millan NC, Gomez-Fernandez C, et al. Review of Current Advances in Serologic Testing for COVID-19. Am J Clin Pathol (2020) 154:293-304. doi: 10.1093/ajcp/aqaa112

23. Shi AC, Ren P. SARS-CoV-2 Serology Testing: Progress and Challenges. J Immunol Methods (2021) 494:113060. doi: 10.1016/j.jim.2021.113060

24. Mohit E, Rostami Z, Vahidi H. A Comparative Review of Immunoassays for COVID-19 Detection. Expert Rev Clin Immunol (2021) 0:null. doi: 10.1080/ 1744666X.2021.1908886

25. Kristiansen PA, Page M, Bernasconi V, Mattiuzzo G, Dull P, Makar K, et al. WHO International Standard for Anti-SARS-CoV-2 Immunoglobulin. Lancet (2021) 397:1347-8. doi: 10.1016/S0140-6736(21)00527-4

26. Expert Committee on Biological Standardization. Available at: https://www. who.int/our-work/access-to-medicines-and-health-products/expertcommittee-on-biological-standardization (Accessed May 15, 2021). 
27. COVID-19 Clinical Management: Living Guidance. Available at: https://www. who.int/publications/i/item/WHO-2019-nCoV-clinical-2021-1 (Accessed May 18, 2021).

28. First WHO International Standard Anti-SARS-CoV-2 Immunoglobulin (Human). Available at: https://www.nibsc.org/products/brm_product_ catalogue/detail_page.aspx?catid=20/136 (Accessed May 18, 2021).

29. Amanat F, Stadlbauer D, Strohmeier S, Nguyen THO, Chromikova V, McMahon M, et al. A Serological Assay to Detect SARS-CoV-2 Seroconversion in Humans. Nat Med (2020) 26:1033-6. doi: 10.1038/s41591-020-0913-5

30. Manisty C, Treibel TA, Jensen M, Semper A, Joy G, Gupta RK, et al. Time Series Analysis and Mechanistic Modelling of Heterogeneity and SeroReversion in Antibody Responses to Mild SARS-CoV-2 Infection. EBioMedicine (2021) 65:103259. doi: 10.1016/j.ebiom.2021.103259

31. Manisty C, Otter AD, Treibel TA, McKnight Á, Altmann DM, Brooks T, et al. Antibody Response to First BNT162b2 Dose in Previously SARS-CoV-2-Infected Individuals. Lancet (2021) 397:1057-8. doi: 10.1016/S0140-6736(21)00501-8

32. Xiong X, Qu K, Ciazynska KA, Hosmillo M, Carter AP, Ebrahimi S, et al. A Thermostable, Closed SARS-CoV-2 Spike Protein Trimer. Nat Struct Mol Biol (2020) 27:934-41. doi: 10.1038/s41594-020-0478-5

33. Baxendale HE, Wells D, Gronlund J, Nadesalingam A, Paloniemi M, Carnell G, et al. Critical Care Workers Have Lower Seroprevalence of SARS-CoV-2 IgG Compared With non-Patient Facing Staff in First Wave of COVID19. medRxiv (2020) 2020:11. doi: 10.1101/2020.11.12.20145318

34. Hyseni I, Molesti E, Benincasa L, Piu P, Casa E, Temperton NJ, et al. Characterisation of SARS-CoV-2 Lentiviral Pseudotypes and Correlation Between Pseudotype-Based Neutralisation Assays and Live Virus-Based Micro Neutralisation Assays. Viruses (2020) 12. doi: 10.3390/v12091011

35. Cantoni D, Mayora-Neto M, Temperton N. The Role of Pseudotype Neutralization Assays in Understanding SARS CoV-2. Oxf Open Immunol (2021) 2:iqab005. doi: 10.1093/oxfimm/iqab005

36. Papa G, Mallery DL, Albecka A, Welch LG, Cattin-Ortolá J, Luptak J, et al. Furin Cleavage of SARS-CoV-2 Spike Promotes But Is Not Essential for Infection and Cell-Cell Fusion. PloS Pathog (2021) 17:e1009246. doi: 10.1371/ journal.ppat.1009246

37. Ashraf N, Zino S, MacIntyre A, Kingsmore D, Payne AP, George WD, et al. Altered Sirtuin Expression Is Associated With Node-Positive Breast Cancer. Br J Cancer (2006) 95:1056-61. doi: 10.1038/sj.bjc.6603384

38. Ritz C, Baty F, Streibig JC, Gerhard D. Dose-Response Analysis Using R. PloS One (2015) 10:e0146021. doi: 10.1371/journal.pone.0146021

39. R: A Language and Environment for Statistical Computing. Available at: https://www.gbif.org/tool/81287/r-a-language-and-environment-forstatistical-computing (Accessed May 11, 2021).

40. Tuaillon E, Bolloré K, Pisoni A, Debiesse S, Renault C, Marie S, et al. Detection of SARS-CoV-2 Antibodies Using Commercial Assays and Seroconversion Patterns in Hospitalized Patients. J Infect (2020) 81:e39-45. doi: 10.1016/ j.jinf.2020.05.077

41. Afzal N, Tariq N, Raza S, Shakeel D. Diagnostic Accuracy of ElectroChemiluminescence Immunoassay Anti-SARS-CoV-2 Serological Test. Cureus 13. doi: $10.7759 /$ cureus. 12588

42. Anderson EM, Goodwin EC, Verma A, Arevalo CP, Bolton MJ, Weirick ME, et al. Seasonal Human Coronavirus Antibodies Are Boosted Upon SARS-CoV-2 Infection But Not Associated With Protection. Cell (2021) 184:1858-64.e10. doi: 10.1016/j.cell.2021.02.010

43. Röltgen K, Powell AE, Wirz OF, Stevens BA, Hogan CA, Najeeb J, et al. Defining the Features and Duration of Antibody Responses to SARS-CoV-2 Infection Associated With Disease Severity and Outcome. Sci Immunol (2020) 5. doi: 10.1126/sciimmunol.abe0240

44. Seow J, Graham C, Merrick B, Acors S, Pickering S, Steel KJA, et al. Longitudinal Observation and Decline of Neutralizing Antibody Responses in the Three Months Following SARS-CoV-2 Infection in Humans. Nat Microbiol (2020) 5:1598-607. doi: 10.1038/s41564-020-00813-8

45. Hall VJ, Foulkes S, Charlett A, Atti A, Monk EJM, Simmons R, et al. SARSCoV-2 Infection Rates of Antibody-Positive Compared With AntibodyNegative Health-Care Workers in England: A Large, Multicentre, Prospective Cohort Study (SIREN). Lancet Lond Engl (2021) 397:1459-69. doi: $10.1016 /$ S0140-6736(21)00675-9
46. Krammer F. Correlates of Protection From SARS-CoV-2 Infection. Lancet (2021) 397:1421-3. doi: 10.1016/S0140-6736(21)00782-0

47. Peterhoff D, Glück V, Vogel M, Schuster P, Schütz A, Neubert P, et al. A Highly Specific and Sensitive Serological Assay Detects SARS-CoV-2 Antibody Levels in COVID-19 Patients That Correlate With Neutralization. Infection (2021) 49:75-82. doi: 10.1007/s15010-020-01503-7

48. Earle KA, Ambrosino DM, Fiore-Gartland A, Goldblatt D, Gilbert PB, Siber GR, et al. Evidence for Antibody as a Protective Correlate for COVID-19 Vaccines. Infect Dis (except HIV/AIDS) (2021) 39(32):4423-28. doi: 10.1101/ 2021.03.17.20200246

49. Clift D, McEwan WA, Labzin LI, Konieczny V, Mogessie B, James LC. Schuh M. A Method for the Acute and Rapid Degradation of Endogenous Proteins. Cell (2017) 171:1692-1706.e18. doi: 10.1016/j.cell.2017.10.033

50. Sigal LJ, Crotty S, Andino R, Rock KL. Cytotoxic T-Cell Immunity to VirusInfected non-Haematopoietic Cells Requires Presentation of Exogenous Antigen. Nature (1999) 398:77-80. doi: 10.1038/18038

51. McAndrews KM, Dowlatshahi DP, Dai J, Becker LM, Hensel J, Snowden LM, et al. Heterogeneous Antibodies Against SARS-CoV-2 Spike Receptor Binding Domain and Nucleocapsid With Implications for COVID-19 Immunity. JCI Insight (2020) 5. doi: 10.1172/jci.insight. 142386

52. Russell MW, Moldoveanu Z, Ogra PL, Mestecky J. Mucosal Immunity in COVID-19: A Neglected But Critical Aspect of SARS-CoV-2 Infection. Front Immunol (2020) 11:611337. doi: 10.3389/fimmu.2020.611337

53. Varadhachary A, Chatterjee D, Garza J, Garr RP, Foley C, Letkeman A, et al. Salivary Anti-SARS-CoV-2 IgA as an Accessible Biomarker of Mucosal Immunity Against COVID-19. medRxiv (2020), 2020.08.07.20170258. doi: 10.1101/ 2020.08.07.20170258

54. Sterlin D, Mathian A, Miyara M, Mohr A, Anna F, Claër L, et al. IgA Dominates the Early Neutralizing Antibody Response to SARS-CoV-2. Sci Transl Med (2021) 13. doi: 10.1126/scitranslmed.abd2223

55. Cervia C, Nilsson J, Zurbuchen Y, Valaperti A, Schreiner J, Wolfensberger A, et al. Systemic and Mucosal Antibody Responses Specific to SARS-CoV-2 During Mild Versus Severe COVID-19. J Allergy Clin Immunol (2021) 147:545-57.e9. doi: 10.1016/j.jaci.2020.10.040

56. Liu S, Lu S. Antibody Responses in COVID-19 Patients. J BioMed Res (2020) 34:410-5. doi: 10.7555/JBR.34.20200134

57. Gaebler C, Wang Z, Lorenzi JCC, Muecksch F, Finkin S, Tokuyama M, et al. Evolution of Antibody Immunity to SARS-CoV-2. Nature (2021) 591:639-44. doi: 10.1038/s41586-021-03207-w

58. Li K, Huang B, Wu M, Zhong A, Li L, Cai Y, et al. Dynamic Changes in AntiSARS-CoV-2 Antibodies During SARS-CoV-2 Infection and Recovery From COVID-19. Nat Commun (2020) 11:6044. doi: 10.1038/s41467-020-19943-y

Conflict of Interest: DAW, MF, RW and JH are affiliated to the company DIOSynVax. JC-O holds a position as vaccinology consultant at Oxford Expression Technologies, Ltd.

The remaining authors declare that the research was conducted in the absence of any commercial or financial relationships that could be construed as a potential conflict of interest.

Publisher's Note: All claims expressed in this article are solely those of the authors and do not necessarily represent those of their affiliated organizations, or those of the publisher, the editors and the reviewers. Any product that may be evaluated in this article, or claim that may be made by its manufacturer, is not guaranteed or endorsed by the publisher.

Copyright $\odot 2021$ Castillo-Olivares, Wells, Ferrari, Chan, Smith, Nadesalingam, Paloniemi, Carnell, Ohlendorf, Cantoni, Mayora-Neto, Palmer, Tonks, Temperton, Peterhoff, Neckermann, Wagner, Doffinger, Kempster, Otter, Semper, Brooks, Albecka, James, Page, Schwaeble, Baxendale and Heeney. This is an open-access article distributed under the terms of the Creative Commons Attribution License (CC BY). The use, distribution or reproduction in other forums is permitted, provided the original author(s) and the copyright owner(s) are credited and that the original publication in this journal is cited, in accordance with accepted academic practice. No use, distribution or reproduction is permitted which does not comply with these terms. 